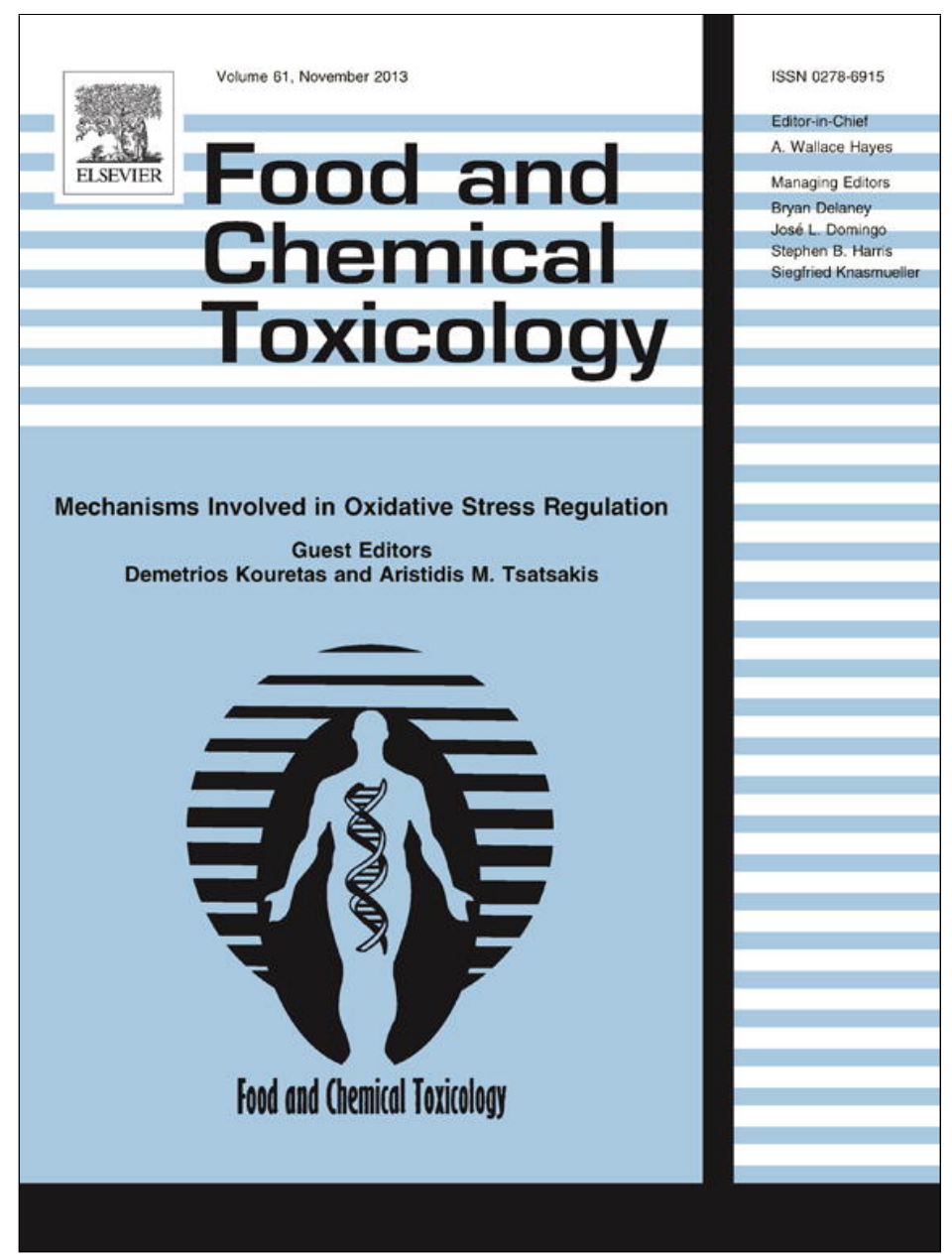

This article appeared in a journal published by Elsevier. The attached copy is furnished to the author for internal non-commercial research and education use, including for instruction at the authors institution and sharing with colleagues.

Other uses, including reproduction and distribution, or selling or licensing copies, or posting to personal, institutional or third party websites are prohibited.

In most cases authors are permitted to post their version of the article (e.g. in Word or Tex form) to their personal website or institutional repository. Authors requiring further information regarding Elsevier's archiving and manuscript policies are encouraged to visit: 


\title{
Antioxidant effects of resveratrol in cardiovascular, cerebral and metabolic diseases
}

\author{
Albino Carrizzo ${ }^{\mathrm{a}}$, Maurizio Forte ${ }^{\mathrm{b}}$, Antonio Damato ${ }^{\mathrm{a}}$, Valentina Trimarco ${ }^{\mathrm{c}}$, Francesco Salzano ${ }^{\mathrm{d}}$, \\ Michelangelo Bartolo ${ }^{\mathrm{e}}$, Anna Maciag ${ }^{\mathrm{f}}$, Annibale A. Puca ${ }^{\mathrm{f}, \mathrm{g}}$, Carmine Vecchione ${ }^{\mathrm{a}, \mathrm{g}, *}$ \\ ${ }^{a}$ Vascular Physiopathology Unit, IRCCS INM Neuromed, Pozzilli (IS), Italy \\ ${ }^{\mathrm{b}}$ Department of Biology, University of Naples "Federico II", Naples, Italy \\ ${ }^{\mathrm{c}}$ Department of Neuroscience, University of Naples "Federico II", Naples, Italy \\ ${ }^{\mathrm{d}}$ Department of Surgical, Oncology and Dentistry Disciplines, University of Palermo, Italy \\ ${ }^{\mathrm{e}}$ NeuroRehabilitation Unit, IRCCS INM Neuromed, Pozzilli (IS), Italy \\ ${ }^{\mathrm{f}}$ Cardiovascular Research Unit, IRCCS Multimedica, Milan, Italy \\ ${ }^{\mathrm{g}}$ Department of Medicine and Surgery, University of Salerno, Salerno, Italy
}

\section{A R T I C L E I N F O}

\section{Article history:}

Available online 18 July 2013

\section{Keywords:}

Oxidative stress

Nitric oxide

Antioxidant

Cardiovascular

Brain

Diabetes

\begin{abstract}
A B S T R A C T
Resveratrol-a natural polyphenolic compound-was first discovered in the 1940s. Although initially used for cancer therapy, it has shown beneficial effects against most cardiovascular and cerebrovascular diseases. A large part of these effects are related to its antioxidant properties. Here we review: (a) the sources, the metabolism, and the bioavailability of resveratrol; (b) the ability of resveratrol to modulate redox signalling and to interact with multiple molecular targets of diverse intracellular pathways; (c) its protective effects against oxidative damage in cardio-cerebro-vascular districts and metabolic disorders such as diabetes; and (d) the evidence for its efficacy and toxicity in humans. The overall aim of this review is to discuss the frontiers in the field of resveratrol's mechanisms, bioactivity, biology, and healthrelated use.
\end{abstract}

(c) 2013 Elsevier Ltd. All rights reserved.

\section{Introduction}

\subsection{Structure and history of resveratrol}

Resveratrol-3,4',5-trihydroxy-trans-stilbene (MW: 228.2)-is a natural non-flavonoid polyphenol compound containing a stilbene structure similar to that of estrogen diethylstilbestrol (Fig. 1a). It is a fat-soluble compound existing in cis, trans-, and piceid isomeric forms (Fig. 1b). It was first isolated in 1940 from the roots of white hellebore (Veratum grandiflorum O. Loes) and later, in 1963, from the roots of Polygonum cupsidatum, a plant used in traditional Chinese and Japanese medicine (Nonomura et al., 1963). Resveratrol has been in use since ancient times as an Indian herbal preparation termed 'Darakchasava', which is derived from fermented grapes. Remarkably, the effects described for Darakchasava more than 4500 years ago (Singh et al., 2013) are the same described for resveratrol today. Today, Darakchasava is produced by several pharmaceutical companies and contains about 1.3-6.0 mg/L resveratrol (Paul et al., 1999). Despite its ancient discovery, the first real interest in resveratrol came in 1992 when it was postulated to

\footnotetext{
* Corresponding author at: Vascular Pathophysiology Unit, IRCCS INM Neuromed, Pozzilli (IS), Italy. Tel.: +39 0865915229; fax: +39 0865927575.

E-mail address: cvecchione@unisa.it (C. Vecchione).
}

explain some of the cardio-protective effects of red wine (Siemann and Creasy, 1992). It was suggested to be the solution to the "French Paradox", a term used to describe the observation that the French population had a very low incidence of cardiovascular disease despite a high consumption of wine and saturated fat (Liu et al., 2007). In 1997, Jang and colleagues reported that resveratrol acts as a chemo-preventive agent, due to its ability to inhibit carcinogenesis at multiple stages (Jang et al., 1997). More recently, anti-inflammatory and antioxidant properties have been reported also (Baur and Sinclair, 2006; Vang et al., 2011), so today it has become a highly important natural active ingredient with potential therapeutic effects and market prospects.

\subsection{Sources of resveratrol}

Resveratrol is produced by various plants as a defense against stress, injury, excessive sunlight, ultraviolet radiation, infection, and invading fungi (Singh et al., 2013). For example, the roots of the plant $P$. cuspidatum, much cultivated in Asia, provides a rich source of resveratrol from which commercially available trans-resveratrol (98\% pure) is isolated by high-speed counter-current chromatography (Yang et al., 2001). Resveratrol is also considered a nutraceutical present in grapes, peanuts, pine trees, cassia and other plants, and many food products (Ramprasath et al., 2010; 
Soleas et al., 1997). In wine, the concentration of resveratrol varies: red wines contain between 0.2 and $5.8 \mathrm{mg} / \mathrm{L}$, depending upon the grape variety, whereas white wines contain $\sim 0.68 \mathrm{mg} / \mathrm{L}$ (RomeroPérez et al., 1999; Sato et al., 1997). This variation derives from the fact that red wine is extracted with the grape skin intact, whereas white wine is fermented after removal of the skin. Red wine contains more trans-resveratrol than white wine, whereas white has a higher concentration of cis-resveratrol (Feijóo et al., 2008). Concentrations of resveratrol in some natural foods are given in Table 1.

\subsection{Metabolism of resveratrol}

In rats and humans, resveratrol is a molecule involved in the enterohepatic cycle of metabolism. In particular, after resveratrol is taken up rapidly by enterocytes, it is metabolized to glucuronide- (3-O-glucuronide and 4'-O-glucuronide) and sulfate-conjugates (3-0-sulfate), which are secreted back into the intestine where they may be deconjugated and reabsorbed or excreted in the feces (Walle et al., 2004; Marier et al., 2002). The enterohepatic cycle thus reduces the concentration of the free compound reaching target tissues. So, the low concentration of resveratrol found in blood is likely explained by this enterohepatic cycle and its rapid metabolism in the liver. Apart from dihydroresveratrol, the major metabolites formed are the glucuronide- and sulfate-conjugates, including disulfates and mixed sulfate-glucuronides (Wang et al., 2005). Concentrations of these metabolites are reported to be higher than resveratrol post-absorption and to have longer half-lives (Andres-Lacueva et al., 2009; Polycarpou et al., 2013). In fact, the majority of orally dosed resveratrol is found in urine as sulfateor glucuronic acid-conjugates (Singh et al., 2013). In particular, the proportion of glucuronide- and sulfate-metabolites are reported to change depending on the tissue and species considered (Juan et al., 2010; Azorín-Ortuño et al., 2011): glucuronide<smiles>Oc1ccc(/C=C/c2cc(O)cc(O)c2)cc1</smiles>

b
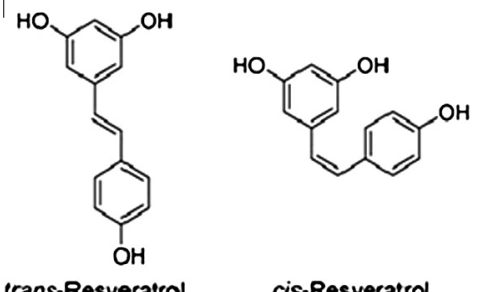

cis-Resveratrol

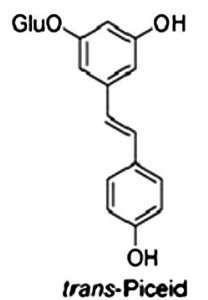

trans-Piceid
Fig. 1. (a) Structure of resveratrol. (b) Structures of trans and cis isomers of resveratrol and piceid.

Table 1

Resveratrol content in certain natural foods (Prasad, 2012).

\begin{tabular}{ll}
\hline Food stuff & Concentration range \\
\hline Grapes & $0.16-3.54 \mu \mathrm{g} / \mathrm{g}$ \\
Dry grape skin & $\sim 24.06 \mu \mathrm{g} / \mathrm{g}$ \\
Red grape juice & $\sim 0.5 \mathrm{mg} / \mathrm{L}$ \\
White grape juice & $\sim 0.05 \mathrm{mg} / \mathrm{L}$ \\
Red wine & $0.1-14.5 \mathrm{mg} / \mathrm{L}$ \\
White wine & $0.1-2.1 \mathrm{mg} / \mathrm{L}$ \\
Peanuts & $0.02-1.92 \mu \mathrm{g} / \mathrm{g}$ \\
Pistachios & $0.09-1.67 \mu \mathrm{g} / \mathrm{g}$ \\
\hline
\end{tabular}

conjugates are reported to be the main metabolites in rodents, whereas primarily sulfates are found in humans (Walle, 2011); moreover, the quantity of glucuronides is higher than sulfates in rat testes and liver, but not in lung (Juan et al., 2010). As a result, many authors are beginning to investigate the effects of resveratrol metabolites on in vitro and in vivo models: for example, resveratrol 3-O-D-sulfate, as well as resveratrol 3-O-D-glucuronide and resveratrol 4-O-D-glucuronide, was found to inhibit cycloxygenase (COX1 and COX2) (Calamini et al., 2010), whereas 3-O-D-sulfate and resveratrol 4-O-D-glucuronide were reported to reduce triacylglycerol content in 3T3-L1 adipocytes (Lasa et al., 2012). Recently, Polycarpou et al. demonstrated that resveratrol glucoronides are able to arrest the growth of different human colon cancer cells (Polycarpou et al., 2013). Thus, many of the effects reported for resveratrol may be due to the action of resveratrol's metabolites.

\subsection{Bioavailability of resveratrol and plasma levels}

Many studies have shown that resveratrol, like other polyphenols, has very low bioavailability (Goldberg et al., 2003). The bioavailability and pharmacokinetics of resveratrol have been studied in humans and in animal models. In humans, resveratrol is rapidly taken up after oral consumption of a low dose, with the plasma resveratrol concentration peaking about $30 \mathrm{~min}$ after consumption (Goldberg et al., 2003); in rats, the plasma half-life of resveratrol was reported to be 12-15 min after oral administration (Gescher and Steward, 2003). A study performed by Walle et al. using ${ }^{14} \mathrm{C}$-trans-resveratrol ( $25 \mathrm{mg}$ orally) in humans showed that $70 \%$ of the resveratrol dose was absorbed by the body (Walle et al., 2004); a similar finding ( $50 \%)$ was reported for rats (Marier et al., 2002). The glucuronide- and sulfate-conjugated metabolites of resveratrol peaked in plasma at 30-60 min post-administration, with a plasma half-life of $9.2 \mathrm{~h}$. (Walle et al., 2004). In contrast, only small amounts of unmodified resveratrol $(<5 \mathrm{ng} / \mathrm{mL})$ were detected in plasma in a similar timeframe (Singh et al., 2013). In another study conducted on mice, rats, and humans, it was shown that within $24 \mathrm{~h}$ after administration of $0.03 \mathrm{mg} / \mathrm{kg}$ body weight (BW) resveratrol, nearly $50 \%$ of the resveratrol was excreted in the urine. However, because $<25 \%$ of the resveratrol was found in the urine with a dose of $1 \mathrm{mg} / \mathrm{kg} \mathrm{BW}$, these results suggest that resveratrol undergoes rapid gastrointestinal absorption in all the three species studied (Meng et al., 2004).

The amount of resveratrol ingested from dietary sources, such as red wine and juices, rarely exceeds $5 \mathrm{mg} / \mathrm{L}$ and often results in plasma levels that are either not detectable or several orders of magnitude below the micromolar concentrations that are employed in experimentation in vitro, i.e., $\sim 32 \mathrm{nM}$ to $100 \mu \mathrm{M}$ (Smoliga et al., 2011). For example, administration of about $25 \mathrm{mg}$ resveratrol resulted in plasma concentrations of the free form that ranged from 1 to $5 \mathrm{ng} / \mathrm{mL}$ (Almeida et al., 2009), and administration of higher doses (up to $5 \mathrm{~g}$ ) increased the plasma resveratrol concentration to about $500 \mathrm{ng} / \mathrm{mL}$ (Boocock et al., 2007). The low doses of resveratrol observed in the plasma after ingestion are very low, as the concentrations used in vitro are not reached. However, due to its lipophilic character, tissue levels of resveratrol may be higher than those found in plasma (Timmers et al., 2012). Nonetheless, some of the biological effects of resveratrol are observed at very low concentrations (Waite et al., 2005; Pearce et al., 2008), bringing forward the idea that resveratrol exerts its major effects on intestinal tissue, affecting the rest of the body through secondary effects that are independent of the plasma levels reached by the compound (Baur et al., 2006). In rodent models, the doses employed normally range from as low as $0.1 \mathrm{mg} / \mathrm{kg}$ BW to up to $1000 \mathrm{mg} / \mathrm{kg} \mathrm{BW}$, with even higher or lower doses occasionally being used (Baur et al., 2006). Interestingly, studies show that the bioavailability of resveratrol can be 
Table 2

Antioxidant activity of resveratrol. The antioxidant molecules and enzymes stimulated by resveratrol are given on the left of the table; enzymes down-regulated by resveratrol are given on the right.

\begin{tabular}{|c|c|}
\hline Antioxidant defense & Oxidant machinery \\
\hline $\begin{array}{l}\text { Sirtuin } 1 \\
\text { Peroxisome proliferator-activated receptor- } \gamma \text { coactivator-1 } \alpha \\
\text { GTP cyclohydrolase I } \\
\text { Tetrahydrobiopterin } \\
\text { Superoxide dismutase } \\
\text { Catalase } \\
\text { Glutathione peroxidase } \\
\text { Glutathione reductase } \\
\text { Glutathione-S-transferase } \\
\text { Heme oxygenase-1 } \\
\text { Nuclear factor (erythroid-derived } 2 \text { )-like } 2\end{array}$ & $\begin{array}{r}\text { NADPH-oxidase } \\
\text { Hypoxanthine/xanthine oxidase } \\
\text { Myeloperoxidase } \\
\text { eNOS uncoupling }\end{array}$ \\
\hline
\end{tabular}

enhanced by using more potent resveratrol analogs (i.e. SRT501) (Howells et al., 2011), by enhancing delivery methods, such as liposomal encapsulation (Narayanan et al., 2009), or by combining it with piperine, a natural product from black pepper (Piper spp.) (Johnson et al., 2011).

\subsection{Aims of the review}

Studies performed in vivo and in vitro have shown that resveratrol exerts pleiotropic effects and can prevent or slow the progression of several pathological conditions, including cardiovascular and metabolic diseases, ischemic brain injuries, and cancer (Jang et al., 1997; Inoue et al., 2003), as well as extend lifespan in different organisms and enhance stress resistance (Yang et al., 2013). The aim of the present review is to highlight the antioxidant effects of resveratrol, focusing our attention on cardiovascular, cerebral, and metabolic disorders, such as diabetes, and reporting also the results of the main clinical trials.

\section{Antioxidant properties of resveratrol}

A well-documented method for reducing oxidative stress is to reduce caloric intake by selecting appropriate foods (Nisoli et al., 2005). It is well known that nutrients, whether water soluble or lipid soluble, comprise an important aspect of the antioxidant defense system. Beyond their normal occurrence in cells and tissues of living organisms, free radicals and reactive species are present in the unhealthy foods that people consume every day, inducing undesirable reactions like oxidation of lipids, proteins, nucleic acids, and carbohydrates. An impaired ability to scavenge free radicals and reactive species, as a consequence of decreased levels of antioxidant cellular defense systems or excessive free-radical production, is common in cerebral and cardiovascular diseases in humans and animals (Alissa and Ferns, 2012).

Resveratrol plays a prominent role among the foods exerting an antioxidant activity. The main antioxidant activities of resveratrol are summarized in Table 2 (Rocha et al., 2009; Li et al., 2006; Juan et al., 2005; Kohnen et al., 2007). The data suggest that resveratrol exerts its action in different ways: it scavenges reactive oxygen species (ROS), increasing the activity of enzymes that metabolize ROS, such as superoxide dismutase (SOD), or decreases the activity of enzymes that play a role in ROS production.

\subsection{Impact of resveratrol on cardiovascular diseases}

\subsubsection{Effects of resveratrol on lipid peroxidation}

Oxidative stress is one of the risks of cardiovascular disease (CVD), such as atherosclerosis, and is characterized by the production of free radicals that lead to the oxidation of low density lipoprotein (LDL) (Kovanen and Pentikaïnen, 2003; Puca et al., 2013). It is well known that oxidized LDL accumulates at the site of atherosclerotic lesions (Ramprasath and Jones, 2010), contributing to the formation of macrophage foam cells that induce endothelial dysfunction (Mietus-Snyder et al., 2000), a common marker of CVD. Because it prevents lipid peroxidation, inhibits uptake of oxidized LDL, and inhibits lipoxygenase activity (Maccarrone et al., 1999; Kovanen and Pentikaïnen, 2003), resveratrol is a good candidate for the fight against oxidative stress in atherosclerosis (Fremont et al., 1999; Leighton et al., 1999; Bhavnani et al., 2001; Olas and Wachowicz, 2002). Oxidation of LDL cholesterol is strongly associated with risk of CVD (Holvoet, 2004). In this regard, resveratrol was found in rat liver microsomes to inhibit iron-induced, as well as ultraviolet-irradiated, lipid peroxidation and to prevent LDL oxidation by copper (Fauconneau et al., 1997; Miura et al., 2000); moreover, Rocha et al. found a reduction in oxidized LDL in rats fed on a high fat diet when treated with resveratrol for 45 days at a dose of $1 \mathrm{mg} / \mathrm{kg}$ BW/day (Rocha et al., 2009).

Resveratrol also prevents the oxidation of polyunsaturated fatty acids found in LDL (Miller and Rice-Evans, 1995), inhibits the oxidized LDL uptake in the vascular wall in a dose-dependent manner (Fremont, 2000), and prevents damage caused to lipids by peroxidation (Frankel and Waterhouse, 1993; Leighton et al., 1999). Its effect was found to be stronger than the well-known antioxidant $\alpha$-tocopherol (Frankel and Waterhouse, 1993). The protective effect of resveratrol against lipid peroxidation was also found in the heart of rats exposed to low doses of doxorubicin, an antitumor drug that causes oxidative stress (Dudka et al., 2012), and in the post-ischemic, re-perfused myocardium of rats (Ray et al., 1999).

\subsubsection{Effects of resveratrol on antioxidant mechanisms protecting against oxidative cardiovascular pathophysiology}

It has been recently demonstrated that resveratrol reduces endothelial dysfunction in vessel from dyslipidemic patients with hypertension; this antioxidant action of resveratrol was mediated by upregulation of manganese superoxide dismutase (Mn-SOD) via a mechanism dependent upon nuclear factor (erythroid-derived 2)-like 2 (NRF2) (Carrizzo et al., 2013). This finding in humans was in agreement with experimental models showing that resveratrol was able to increase Mn-SOD expression in the mouse myoblast line $\mathrm{C} 2 \mathrm{C} 12$ via nuclear translocation and activation of sirtuin 1 (SIRT1), a NAD ${ }^{+}$-dependent class III histone deacetylase. In obese rats, Franco et al. found that the activity of both SOD and catalase (CAT) was increased in plasma by the administration of resveratrol, preventing oxidative stress and reducing the risk of hypertension (Franco et al., 2013). Similarly, hepatic expression of SIRT1 and 
Mn-SOD genes was induced in wild-type rats by $0.02 \%$ resveratrol after 4 weeks of treatment (Nakata et al., 2012). The stimulation of Mn-SOD levels was also reported in cultured cardiomyocytes and in coronary artery endothelial cells (Movahed et al., 2012; Ungvari et al., 2009; Tanno et al., 2010). In human aortic smooth muscle cells, it increased the expression of heme oxygenase-1 (HO- 1 ), which degrades pro-oxidant heme to biliverdin/bilirubin, iron, and carbon monoxide, consequently reducing ROS levels (Juan et al., 2005). In vascular smooth muscle cell, resveratrol reduced nicotinamide adenine dinucleotide phosphate (NADPH) oxidase activity induced by angiotensin II, and enhanced SOD activity, promoting a significant decrease in ROS generation (Zhang et al., 2013). Moreover, resveratrol inhibits the expression of NADPH oxidase in cardiovascular tissues and reduces $\mathrm{O}_{2}^{-}$production from mitochondria (Li et al., 2013). Recently, it has been demonstrated that resveratrol-mediated upregulation of GCH-1 (GTP cyclohydrolase I) and BH4 (tetrahydrobiopterin) biosynthesis prevents endothelial nitric oxide synthase (eNOS) uncoupling and reduces ROS production in the vasculature (Carrizzo et al., 2013).

Xanthine oxidase has been shown to be an important source of oxidant production in vascular endothelium (Sabán et al., 2013) and also a contributing factor to oxidative stress during strenuous exercise. On this issue, has been demonstrated that resveratrol inhibits hypoxanthine/xanthine oxidase in mice, reducing ROS generation (Ryan et al., 2010). Moreover, it has been reported that resveratrol treatment decreases ROS levels in high-capacity runner rats especially in endurance racing: in particular, it increased the aerobic performance and upper-limb strength of these rats. This beneficial effect is mediated by enhanced mitochondrial biogenesis, with activation of the AMPK-SIRT1-PGC- $1 \alpha$ pathway (Hart et al., 2013). Also, resveratrol inhibited oxidative stress in vivo by scavenging ROS and attenuating peroxyl radicals, hydrogen peroxide $\left(\mathrm{H}_{2} \mathrm{O}_{2}\right)$, and superoxide radical $\left({ }^{-*} \mathrm{O}_{2}\right)$ ( $\mathrm{Liu}$ et al., 2003; Chen et al., 2004). In rat pheochromocytoma (PC12) cells, which are characterized by a high level of catecholamines, 1-100 mmol/L resveratrol inhibited production of ROS (Jang and Surh, 2001).

Resveratrol has also been shown to inhibit ${ }^{-*} \mathrm{O}_{2}$ and $\mathrm{H}_{2} \mathrm{O}_{2}$ produced in murine macrophages stimulated by lipopolysaccharides (LPS) or phorbol esters (Martinez and Moreno, 2000). In embryonic rat cardiac cells, it prevented mitochondrial damage induced by $\mathrm{H}_{2} \mathrm{O}_{2}$ (He et al., 2012). Moreover, resveratrol activates an important survival signal pathway consisting in $A_{1}$ and $A_{3}$ adenosine receptor-mediated activation of the PI3K-AKT pathway and the cAMP response element-binding protein (CREB), promoting upregulation of Bcl-2 and, hence, protecting cardiac tissue from cell death ( $\mathrm{Li}$ et al., 2012).

In human platelets, resveratrol significantly lowers the levels of thiol proteins (Olas et al., 2004). It also hampers platelet aggregation and activation: phytoalexin seems to inhibit the interaction of platelets with collagen and thrombin in vitro in isolated platelets and in animal models. The mechanism remain unclear, but it seems that inhibition of prostaglandin $\mathrm{H}$ synthase 1 and cyclooxygenase- 1 over COX2 represent possible mechanisms for the anti-platelet aggregation effect of resveratrol (Borriello et al., 2010).

In a wide variety of cells, such as myeloid, lymphoid, and epithelial cells, resveratrol has been shown to prevent the production of ROS induced by tumor necrosis factor (TNF $\alpha$ ) (Manna et al., 2000). In aortic endothelial cells, resveratrol (100 nM) was found to prevent TNF $\alpha$-induced oxidative stress through a reduction in NADPH oxidase activity and the production of $\mathrm{H}_{2} \mathrm{O}_{2}$ and ${ }^{-*} \mathrm{O}_{2}$ (Vecchione et al., 2009a,b). Recently, Wang et al. demonstrated that resveratrol decreases apoptosis induced by oxidative stress in vascular adventitial fibroblasts of rats treated with TNF- $\alpha$, acting by activating SIRT1 (Wang et al., 2013).
Other mechanisms through which resveratrol has been suggested to exert CVD-preventing antioxidant effects are:

(a) competition with coenzyme $\mathrm{Q}$, decreasing oxidative chain complex III, and increasing endogenous antioxidants and phase 2 enzymes in rat cardiomyocytes (Cao and Li, 2004);

(b) antioxidant effects against linoleic acid peroxidation in sodium dodecyl sulfate and cetyltrimethylammonium bromide micelles (Fang et al., 2002; Fang and Zhou, 2008);

(c) maintenance of glutathione levels in oxidatively stressed human peripheral blood mononuclear cells, and elevation of glutathione levels in human lymphocytes activated by $\mathrm{H}_{2} \mathrm{O}_{2}$ (Losa, 2003; Olas et al., 2004). A strong dose-dependent induction of antioxidant genes was demonstrated when rats were supplemented with $0.3,1$, and $3 \mathrm{~g} / \mathrm{kg} \mathrm{BW/}$ day resveratrol for 28 days (Hebbar et al., 2005);

(d) interaction with AMP-activated protein kinase (AMPK) in diabetic LDL-receptor-deficient mice (Zang et al., 2006), and PPAR $\gamma$ coactivator (PGC)- $1 \alpha$ in mouse cardiac tissue (Lagouge et al., 2006);

(e) reduction in the rate of cytochrome $\mathrm{C}$ oxidation by hydroxyl radicals (Turrens et al., 1997). Jiian et al. reported that resveratrol significantly reduced cytochrome $C$ protein levels in the heart tissue of rats subjected to trauma-hemorrhage; the authors suggest that resveratrol may be important for mitochondrial membrane integrity, leading to a reduction of ROS generation (Jian et al., 2012)

\subsubsection{Effects of resveratrol on nitric oxide metabolism}

Nitric oxide (NO) plays a critical role in maintaining cardiovascular homeostasis (Dudzinski et al., 2006; Dudzinski and Michel, 2007; Puca et al., 2012). In the vasculature, NO is constitutively synthesized by eNOS and acts by relaxing vascular smooth muscle cells and upregulating blood flow, and so prevents thrombogenic and atherogenic processes. It has been demonstrated both in vitro and in vivo that resveratrol is involved in NO metabolism. For example, $30 \mu \mathrm{M}$ resveratrol inhibited the contractile response to phenylephrine in isolated rat aorta (Chen and Pace-Asciak, 1996). Similarly, $70 \mu \mathrm{M}$ resveratrol caused relaxation of isolated human saphenous vein and internal mammary artery rings (Rakici et al., 2005), and relaxed porcine arterial rings pre-contracted with $\mathrm{KCl}$ (Li et al., 2006). In those studies, the inhibitory effect of resveratrol was reversed by removal of the endothelium or by inhibition of eNOS. Orallo et al. reported that resveratrol $(1-30 \mu \mathrm{M})$ relaxed the contractile response of rat aortic rings to phenylephrine and $\mathrm{KCl}$ in an NO-dependent manner (Orallo et al., 2002); however, it was suggested that resveratrol does not affect eNOS activity, but instead inhibits NADH/NADPH oxidase, with a decreased reduction in superoxide generation, leading to improved NO bioavailability. Resveratrol rapidly increased NO production in cultured endothelial EA.hy926 cells, although at a high concentration $(10 \mu \mathrm{M})$ (Wallerath et al., 2002). In bovine aortic endothelial cells, 100 $\mathrm{nM}$ resveratrol for $15 \mathrm{~min}$ was found to increase NO production through phosphorylation of AKT, extracellular signal-regulated kinase (ERK)1/2, and eNOS (Wang et al., 2011). Klinge et al. proposed that resveratrol increases NO production through membrane estrogen receptors (ERs) in bovine aortic cells, human umbilical vein cells, and human microvascular endothelial cells (Klinge et al., 2005,2008 ) by rapid activation of Src and ERK $1 / 2$, leading to eNOS activation. However, as demonstrated by studies on isolated porcine coronary arteries (Li et al., 2006) and murine endothelial f-2 cells (Takahashi et al., 2009), ER antagonists do not inhibit resveratrol-stimulated NO production.

Wallerath et al. reported that the treatment of cultured endothelial cells with resveratrol $(10-100 \mu \mathrm{m})$ for $24-72 \mathrm{~h}$ upregulated eNOS mRNA and protein expression levels, resulting in increased 
production of NO (Wallerath et al., 2002; Conti et al., 2012). Similarly, other studies confirmed that high concentrations of resveratrol significantly enhanced eNOS gene expression and enzyme activity, and hence NO production, in in vitro assays (Räthel et al., 2007; Appeldoorn et al., 2009). In contrast, Nicholson et al. (Nicholson et al., 2010) reported that exposure of HUVECs to nanomolar concentrations of resveratrol for $24 \mathrm{~h}$ increased the eNOS mRNA level, although eNOS protein and NO production were not affected. In the same cell line, Takahashi et al. demonstrated that $50 \mathrm{nM}$ resveratrol did not alter the eNOS protein level or NO production after $24 \mathrm{~h}$ of treatment, whereas daily treatment for 5 days significantly increased both eNOS protein and NO production without producing any cytotoxic effects (Takahashi and Nakashima, 2011). Resveratrol also increased the synthesis of NO in ischemic re-perfused rat tissue (Hattori et al., 2002) and preserved eNOS phosphorylation in diabetic type $2(\mathrm{db} / \mathrm{db})$ mice (Zhang et al., 2009).

\section{Impact of resveratrol on cerebrovascular diseases}

Many studies have reported that the central nervous system is targeted by resveratrol. This compound is in fact able to pass the blood-brain barrier (Baur et al., 2006). Regarding its radical-scavenging activity, structural studies demonstrated that the hydroxyl group at the $4^{\prime}$ position of resveratrol is much easier to subject to oxidation than other hydroxyl groups in the antioxidant reaction (Caruso et al., 2004). Intraperitoneal administration of resveratrol exerted neuroprotective effects, upregulating several endogenous antioxidant enzymes, such as SOD and CAT, in the brain of healthy rats (Mokni et al., 2007). Regarding the various isoforms of SOD, SOD2 plays a more important role against oxidant-induced mitochondrial oxidative stress and cytotoxicity in neuronal cells (Vincent et al., 2007). Fukui et al. demonstrated in HT22 neural cells that the neuroprotective effect of resveratrol after glutamate-induced cytotoxicity is largely independent of its direct antioxidant activity; rather, this effect was mediated by induction of SOD2 expression via activation of the PI3K-AKT-GSK-3 $\beta$ - $\beta$-catenin signaling pathway (Fukui et al., 2010). In rats, prolonged administration of resveratrol improved colchicine-induced cognitive impairment, reduced malondialdehyde-an indicator of lipid peroxidation and nitrite levels-and restored depleted glutathione (GSH), a ROS scavenger (Kumar et al., 2007).

It is interesting that resveratrol might be involved in the attenuation of neuroinflammatory responses because it is able to reduce the concentration of 8-iso-prostaglandin $\mathrm{F} 2 \alpha$, an indicator of freeradical generation in rat microglia (Candelario-Jalil et al., 2007). It has also be shown that resveratrol inhibits COX1, but does not affect the expression of COX2 (Davinelli et al., 2012). Since nuclear factor-k $\beta$ (NF-k $\beta$ ) signaling activation also plays an important role in neurodegeneration, a link between Alzheimer's Disease (AD) and the neuroprotective activity of resveratrol is its ability to reduce, in cultured rat astroglioma C6 cells, the expression of genes modulated by NF-k $\beta$, such as inducible nitric oxide synthase (iNOS), prostaglandin E2 (PGE2), as well as cathepsin and NO (Kim et al., 2006). Resveratrol also attenuates LPS-stimulated NF-k $\beta$ activation in primary murine microglia and astrocytes, suggesting that the inflammatory responses induced by LPS could be limited by resveratrol (Lu et al., 2010).

In experimental models of stroke, Sinha et al. have shown a significant attenuation of malondialdhehyde and reduced GSH in the rat middle-cerebral-artery occlusion model after 21 days of treatment with $20 \mathrm{mg} / \mathrm{kg}$ BW trans-resveratrol (Sinha et al., 2002). Moreover, resveratrol significantly decreased oxidative stress markers, including serum glycated albumin and urinary hydroxyguanosine, in stroke-prone spontaneously hypertensive rats
(Mizutani et al., 2001). Also, studies performed on ischemia-reperfusion models have demonstrated that resveratrol inhibits peroxisome proliferator-activated receptors alpha (PPAR $\alpha$ ) (Inoue et al., 2003) and reduces NF-k $\beta$ p65 expression (Wang et al., 2003).

\subsection{Resveratrol and SIRT1}

Several studies have attributed resveratrol the capacity to stimulate the activity of SIRT1 (Alcaín and Villalba, 2009). Consequently, resveratrol administration appears to mimic caloric restriction (Baur et al., 2006). A calorie-restricted diet has been demonstrated to attenuate $A D$ pathogenesis through an increase in SIRT1 activity in a mouse model of AD (Saiko et al., 2008), and also to reduce $\beta$-amyloid $(\mathrm{A} \beta)$ deposition and $\mathrm{A} \beta$-associated neuropathology in different animal models (Wang et al., 2005; Patel et al., 2005; Gentile et al., 2009). Kim et al. showed in a transgenic AD mouse model that resveratrol reduced neurodegeneration through a decrease in the acetylation of known SIRT1 substrates, for example peroxisome-proliferator-activated receptor gamma coactivator alpha (PGC-1 $\alpha$ ) and p53 (Kim et al., 2006). Resveratrol-activated SIRT1 also reduced amyloid neuropathology in the brains of $\mathrm{Tg} 2576$ mice and protected cells against $A \beta$-induced ROS production (Kelsey et al., 2010). Taking into account that resveratrol can be considered a neuroprotective compound in the context of $\mathrm{AD}$, it can be speculated that the ability to counteract $\mathrm{A} \beta$ toxicity is due to its antioxidant properties, but also due to SIRT1 activation.

The anti-amyloidogenic activity of resveratrol has been reported in several studies: for example, Riviere et al. showed that more than other stilbenes, resveratrol inhibits $\beta$-amyloid peptide polymerization in vitro, even though its anti-amyloidogenic mechanism remained unknown (Rivière et al., 2007). As illustrated by Marambaud and colleagues, resveratrol promotes clearance of intracellular $\mathrm{A} \beta$ by activating proteasomal degradation (Marambaud et al., 2005). Moreover, SIRT1 overexpression reduces A $\beta$ pathology in APP-expressing neuronal cultures by delaying A $\beta$ synthesis (Marambaud et al., 2005; Tang and Chua, 2008). Feng et al. demonstrated that resveratrol disrupts $\mathrm{A} \beta$ hydrogen binding, preventing fibril formation by destabilizing preformed fibrils without affecting oligomerization (Feng et al., 2009). Furthermore, studies have shown that the protective effects of resveratrol on $\beta$-amyloid-induced toxicity are related to activation of PKC or AMPK (Han et al., 2004; Karuppagounder et al., 2009).

\subsection{Resveratrol and Nrf2}

NRF2 is a key regulator of cellular antioxidant responses and appears to be a good candidate for neuroprotection in AD. In fact, NRF2 regulates the expression of genes encoding antioxidant and detoxifying proteins, such as glutathione S-transferase (GST), glutathione synthetase (GSS), HO-1, and $\mathrm{NAD}(\mathrm{P}) \mathrm{H}$-quinone oxidoreductase (Scapagnini et al., 2011). Under basal conditions, NRF2 is sequestered in the cytoplasm by Kelch-like ECH-associating protein 1 (KEAP1), which facilitates its polyubiquitylation and proteasome-mediated degradation. KEAP1 functions as a sensor of stress signals. Exposure to oxidants disrupts the KEAP1-NRF2 complex, stabilizing NRF2 and allowing it to accumulate in the nucleus. NRF2 activates the transcription of its target genes via antioxidant response elements (AREs) in their promoter regions, binding as a heterodimer with members of the Maf and Jun families (Davinelli et al., 2012). To date, only few studies have shown that the activation of NRF2 and of its antioxidant genes by resveratrol treatment is sufficient to protect against AD. However, Chen et al. reported that resveratrol is able to increase the expression of HO-1 and GSH, protecting PC12 cells from oxidative stress via activation of the NRF2-ARE signaling pathway (Chen et al., 2005), which does 
suggest a potential for the treatment of AD. Similarly, resveratrol was able to induce $\mathrm{HO}-1$ in primary neuronal cultures, presumably through the activation of NRF2 (Zhuang et al., 2003). The neuroprotective actions of HO- 1 are attributable to the formation of biliverdin and bilirubin during heme degradation, both of which can serve as ROS scavengers (Otterbein and Choi, 2000; Stocker et al., 2000). In conclusion, NRF2 is an attractive target for the discovery of natural neuroprotective agents, such as resveratrol.

\section{Impact of resveratrol on diabetes}

It has been proposed that oxidative stress caused especially by a sedentary lifestyle and an unhealthy diet is an important risk factor for the development of diabetes. Some studies have proposed resveratrol as a possible candidate for diabetes prevention.

\subsection{Resveratrol and $N A D(P) H$ oxidase}

Activation of $\mathrm{NAD}(\mathrm{P}) \mathrm{H}$ oxidase contributes to vascular oxidative stress in experimental diabetes (Vecchione et al., 2006). In particular, TNF $\alpha$-mediated activation of $N A D(P) H$ oxidase is mainly responsible for the generation of the oxidative stress encountered in the coronary microcirculation in type 2 diabetes (Gao et al., 2007; Vecchione et al., 2007). The ${ }^{-*} \mathrm{O}_{2}$ derived from $\mathrm{NAD}(\mathrm{P}) \mathrm{H}$ oxidase can be dismutased to produce $\mathrm{H}_{2} \mathrm{O}_{2}$ (Papa and Skulachev, 1997) or can be the cause of nitrative stress: in fact, the interaction of ${ }^{-*} \mathrm{O}_{2}$ with $\mathrm{NO}$ produces peroxynitrite, which leads to protein tyrosine nitration generating nitrotyrosine, an index of reactive nitrogen species; it also reduces NO bioavailability, causing endothelial dysfunction (Shah and Channon, 2004). Increased nitrotyrosine stress and peroxynitrite formation are associated with diabetes development, as demonstrated in various studies (Pacher et al., 2007; Frustaci et al., 2000; Pacher and Szabo, 2006). For example, nitrotyrosine content was found to be high in microvasculature endothelial cells of diabetic patients (Ceriello et al., 2002). In the aorta of diabetic mice, resveratrol was found to downregulate $\mathrm{NAD}(\mathrm{P}) \mathrm{H}$ oxidase expression, and thus contributed to a reduction in ${ }^{-*} \mathrm{O}_{2}$ production (Zhang et al., 2009). Aortic nitrotyrosine protein and $\mathrm{H}_{2} \mathrm{O}_{2}$ levels also attenuate after treatment with resveratrol (Zhang et al., 2009). In type 2 diabetic mice, Kitada et al. demonstrated that resveratrol normalized Mn-SOD activity, through a reduction in tyrosine-nitrate modifications and decreased urinary 8-hydroxy2 -deoxyguanosine $(8-\mathrm{OHdG})$, a marker of oxidative stress, and $\mathrm{O}_{2}^{-}$levels (Kitada et al., 2011).

\subsection{Resveratrol and nuclear factor- $k B$}

Hyperglycemia-the hallmark of diabetes-can also induce oxidative stress via several pathways that converge on NF-k $\beta$, the activation of which in turn contributes to a further enhancement of pro-inflammatory cytokines, oxidative stress, and apoptosis (Kern, 2007; Singh et al., 2011). In this context, resveratrol was demonstrated to produce several anti-diabetic effects, such as reduction of circulatory pro-inflammatory cytokines, inhibition of apoptosis, and concomitant enhancement of antioxidant defenses (Lee et al., 2011; Palsamy and Subramanian, 2010; Sharma et al., 2009, 2011; Zhang et al., 2010). It has been documented that short-term treatment of diabetic subjects with resveratrol inhibited the activation of NF-k $\beta$ at transcriptional or post-transcriptional levels (Lee et al., 2009; Zhang et al., 2010). Resveratrol may attenuate the inflammatory process through a reduction of oxidative damage and NF-k $\beta$ activity (Kubota et al., 2009).

\subsection{Resveratrol and oxidative markers}

Oxidation of glucose is another mechanism occurring in diabetes (Maritim et al., 2003). Proteins such as hemoglobin and antioxidant enzymes can be glycate in the presence of a high concentration of oxidated glucose. This leads to a reduction in detoxification of ROS, resulting in lipid-, protein-, and DNA-peroxidation, and, finally, apoptosis (Rains and Jain, 2011). Glycated hemoglobin (HbA1c) is a good marker for diagnosis and prognosis of complications in diabetes, such as retinopathy, nephropathy, and neuropathy (Howlett and Ashwell, 2008). For example, it was shown that reduction of HbA1c by only 1 unit (8-7\%) can reduce the risk of retinopathy by over $30 \%$ (Kowluru and Chan, 2007). Four months of resveratrol supplementation was found to reduce HbA1c levels in diabetic rats (Soufi et al., 2012).

Another good marker of oxidative and antioxidant homeostasis is 8-isoprostane (8-iso-prostaglandin F2 $\alpha$ ), a product of the oxidation of arachidonic acid present in phospholipids (Morrow et al., 1995). It was reported that plasma levels of 8-isoprostane increased with diabetes-induced lipid peroxidation and oxidative stress (Ndisang et al., 2010; Salim et al., 2010). Moreover, retinal 8-isoprostane increased during hypoxia-induced retinopathy (Kimura et al., 2007), and resveratrol reduced 8-isoprostane levels in blood and retinal tissue of normal and diabetic rats, demonstrating that resveratrol has a strong antioxidant effect and attenuates oxidative stress (Soufi et al., 2012).

In diabetes, the attenuation of oxidative stress reduces the level of activated caspases and, thus, reduces apoptosis. In fact, resveratrol was found to modulate embryonic oxidative stress and apoptosis in diabetic pregnancy: in particular, it reduced oxidative stress by restoring the level of reduced glutathione, total thiol, lipid peroxidation, and 4-hydroxy-2-non-enal (HNE) in diabetic dams (Singh et al., 2013).

\section{Toxicity of resveratrol}

Many studies have investigated the toxic effect of resveratrol. Most of the data available, both in human and in animal models, suggest that resveratrol does not have a significant toxic effect in the wide range of concentrations tested (Ramprasath and Jones, 2010). For example, no toxic effects were found in rats after oral administration of $20 \mathrm{mg} / \mathrm{kg} \mathrm{BW} /$ day for 28 days, a dose higher than that produced by one glass of red wine per day (Juan et al., 2002). Moreover, no toxic effects were observed in rats given a supplementation of $300 \mathrm{mg}$ resveratrol/day for 4 weeks. In humans, Boocock et al. found no toxicity after administration of a single dose of up to $5 \mathrm{~g}$ resveratrol (Boocock et al., 2007). In addition, clinical, biochemical, and hematological indices revealed no serious toxic effects in 44 healthy volunteers (10-12 per group) administered resveratrol for 29 days at a daily dose of $0.5,1.0,2.5$, or $5.0 \mathrm{~g}$. (Brown et al., 2010). However, adverse effects found in 28 participants were considered possibly due to resveratrol: common symptoms were gastrointestinal in nature, particularly diarrhea, nausea, and abdominal pain, at a dose of $1 \mathrm{~g}$. Typically, gastrointestinal symptoms occurred $\sim 1 \mathrm{~h}$ after administration, and improved during the course of the day. However, all the events were graded as mild, according to the National Cancer Institute Common Terminology Criteria for Adverse Events (CTCAE) (Ramprasath and Jones, 2010). Based on the these findings, the authors suggested that daily doses of resveratrol for subsequent clinical evaluation should not exceed $1 \mathrm{~g}$. (Brown et al., 2010). Chow et al. reinforced those findings and demonstrated that $1 \mathrm{~g}$ resveratrol taken once daily for 4 week was generally well tolerated in healthy participants (Chow et al., 2010): all the reported adverse events were CTC grade 1 or 2 , with many being mild and transient. The frequency of the side 
Table 3

Summary of clinical trials on antioxidant effects of resveratrol. $\downarrow$, downregualtion; $\uparrow$, upregulation.

\begin{tabular}{|c|c|c|c|c|c|}
\hline References & Sample population & Resveratrol dose & Duration & \multicolumn{2}{|c|}{ Molecular-level effects } \\
\hline Ghanim et al. (2010) & 20 healthy adults & $40 \mathrm{mg}$ & 6 weeks & $\begin{array}{l}\downarrow \text { ROS } \\
\downarrow \text { P47(phox) } \\
\downarrow \text { NFKB } \\
\downarrow \text { JNK-1, } \\
\downarrow \text { PTP-1B }\end{array}$ & $\begin{array}{l}\uparrow \text { TNF- } \alpha \\
\uparrow \text { IL-6 } \\
\uparrow \text { CRP } \\
\uparrow \text { SOCS-3 }\end{array}$ \\
\hline Ghanim et al. (2011) & 4 healthy men and 6 women & $\begin{array}{l}100 \mathrm{mg}+75 \mathrm{mg} \text { grapeskin } \\
\text { polyphenols }\end{array}$ & 1 week & $\begin{array}{l}\downarrow \text { ROS } \\
\downarrow \text { TLR-4 } \\
\downarrow \text { CD14 } \\
\downarrow \text { IL-1 } \beta \\
\downarrow \text { SOCS-3 }\end{array}$ & $\begin{array}{l}\uparrow \mathrm{Nrf}-2 \\
\uparrow \mathrm{NQO}-1 \\
\uparrow \mathrm{GST}-\mathrm{P} 1\end{array}$ \\
\hline Brasnyo et al. (2011) & 19 diabetic men & $5 \mathrm{mg}$ twice daily & 4 weeks, & $\downarrow$ ROS & $\uparrow \mathrm{pAk}$ \\
\hline Timmers et al. (2011) & 11 healthy obese men & $150 \mathrm{mg}$ twice daily & 30 days & $\begin{array}{l}\downarrow \text { glucose } \\
\downarrow \text { insulin } \\
\downarrow \text { ROS }\end{array}$ & $\begin{array}{l}\uparrow \text { AMPK } \\
\uparrow \text { SIRT1 } \\
\uparrow \text { PGC1 } \alpha\end{array}$ \\
\hline Bo et al. (2013) & 50 healthy adult smokers & $500 \mathrm{mg}$ & 30 days & $\begin{array}{l}\downarrow \text { ROS } \\
\downarrow \text { CRP } \\
\downarrow \text { TG }\end{array}$ & \\
\hline
\end{tabular}

The biological effects of resveratrol

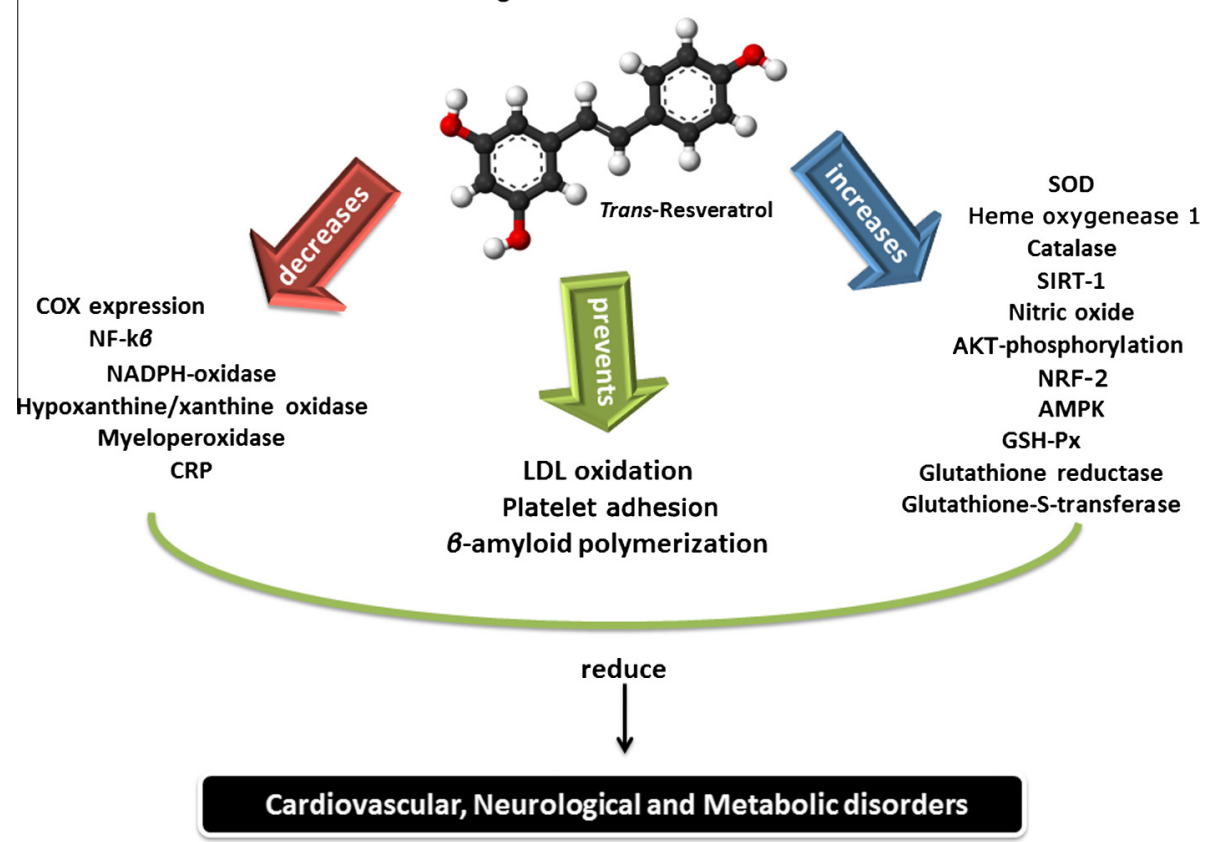

Fig. 2. Representative scheme of the biological effects recruited by resveratrol and their involvement in cardiovascular, metabolic and cerebrovascular diseases.

effects experienced was consistent with that observed in a trial described by Brown et al. (Brown et al., 2010) and in shorter-term studies involving fractionated daily doses (la Porte et al., 2010; Almeida et al., 2009; Nunes et al., 2009).

Finally, it is important to underline that resveratrol can exhibit pro-oxidant activities in the presence of transition metal ions, such as copper, leading to oxidative breakage of cellular DNA (de la Lastra and Villegas, 2007).

\section{Clinical trials on the antioxidant effects of resveratrol}

To date, only a small number of clinical trials on the antioxidant effects of resveratrol have been reported. The most significant clinical trials are summarized in Table 3. Ghanim et al. (2010) investigated the effects of resveratrol on different markers of inflammation and oxidative stress in a randomized placebocontrolled trial: the study was performed on 20 healthy adults receiving a $200 \mathrm{mg} P$. cuspidatum extract supplement containing $40 \mathrm{mg}$ of resveratrol, for 6 weeks. Resveratrol did not alter fasting plasma concentrations of cholesterol (total, LDL, and HDL), triglycerides, or leptin compared with placebo. However, the treatment reduced ROS levels, TNF $\alpha$, and IL-6, and suppressed NF-k $\beta$ in mononuclear cells. Additionally, C-reactive protein (CRP)-another important marker of inflammation-was significantly reduced.

Ghanim et al. also conducted a separate crossover placebo-controlled trial on 10 healthy humans fed with a high-fat, high-carbohydrate meal (Ghanim et al., 2011). The $100 \mathrm{mg}$ resveratrol supplementation used significantly increased NRF2-binding activity following the meal, and significantly increased mRNA expression of important antioxidant enzymes, such as the $\mathrm{NAD}(\mathrm{P}) \mathrm{H}$ dehydrogenase [quinone] 1 (NQO-1) and glutathione S-transferase p1 (GST-p1). Resveratrol also attenuated the postprandial rise in cluster of differentiation 14 (CD14), IL-1 $\beta$ mRNA, and toll-like receptor 4 (TLR4) protein in mononuclear cells, while also 
decreasing plasma endotoxin. These data suggest strong antioxidant and anti-inflammatory effects of resveratrol in response to the high-fat, high-carbohydrate meal and a potential use in reducing the risk of atherosclerosis and diabetes.

Interestingly, in a randomized double-blind placebo-controlled crossover study, $5 \mathrm{mg}$ trans-resveratrol supplementation given twice daily for 4 weeks improved insulin sensitivity and lowered blood glucose levels, delaying its peak (Brasnyo et al., 2011). Among the mechanisms suggested to exert these beneficial effects, the authors indicated decreased oxidative stress and increased AKT phosphorylation.

The metabolic effects of resveratrol have also been studied in obese men (Timmers et al., 2011): supplementation with $75 \mathrm{mg}$ resveratrol for 30 days reduced sleeping- and resting-metabolic rate in the absence of body weight changes; moreover, resveratrol increased SIRT1 protein levels in muscle and reduced blood inflammation markers.

Finally, Bo et al. evaluated the effects of resveratrol on healthy smokers: they found that $500 \mathrm{mg}$ resveratrol for 30 days significantly increased total antioxidant status values (Bo et al., 2013). The authors suggested that resveratrol may reduce the risk of cardiovascular diseases in smokers.

\section{Conclusion and recommendations}

In this review, we have focused our attention on the antioxidant effects of resveratrol and on its molecular mechanisms. The neutralization of free radicals prevents the activation of redox-sensitive molecules involved in the modulation of biological process, such as cell cycle and mitochondrial biogenesis, and of a wide range of chronic diseases, including cardiovascular, neurological, and metabolic disorders (Fig. 2). It is necessary to underline that all antioxidant substances must be used at the proper dose, since high concentrations may induce undesirable effects, such as non-specific reactions with proteins, and decrease antioxidant properties. Although a beneficial "in vitro" antioxidant effect of resveratrol on vessels from patients showing vascular dysfunction is well defined, further clinical trials need to determine resveratrol's mechanism of action, its safety, and its toxicology. In the light of existing data, it is clear that grapes-and wine-should be considered an integral component of fruit- and vegetable-enriched diets that are recommended by health authorities and widely accepted as beneficial for human health and disease prevention.

\section{Conflict of Interest}

The authors declare that there are no conflicts of interest.

\section{List of abbreviations}

$\begin{array}{ll}-{ }^{*} \mathrm{O}_{2} & \begin{array}{l}\text { Superoxide anion } \\ \text { 8- }\end{array} \\ 8- & \quad \text { OHdG } \\ \text { hydroxy-2'-deoxyguanosine } \\ \text { AMPK } & \begin{array}{l}\text { 5' adenosine monophosphate-activated protein } \\ \text { kinase }\end{array} \\ \text { AREs } & \text { Antioxidant response elements } \\ \mathrm{A} \beta & \text { Beta amyloid } \\ \mathrm{BBB} & \text { Blood-brain barrier } \\ \mathrm{Bcl}-2 & \text { B-cell lymphoma 2 } \\ \mathrm{BH} 4 & \text { Tetrahydrobiopterin } \\ \text { BW } & \text { Body weight } \\ \text { CAT } & \text { Catalase } \\ \text { CD14 } & \text { Cluster of differentiation } 14 \\ \text { COX } & \text { Cycloxigenase }\end{array}$

CREB cAMP response element-binding protein

CRP C-reactive protein

CTCAE Common Terminology Criteria for Adverse Events

CVD Cardiovascular diseases

eNOS Endothelial nitric oxide synthase

ER Estrogen receptors

ERK Extracellular signal-regulated kinase

GCH-1 GTP cyclohydrolase I

GSH Reduced glutathione

GSK-3 $\beta$ Glycogen kinase 3 beta

GSS Glutathione synthetase

GST Glutathione S-transferase

GST-p1 Glutathione S-transferase p1

$\mathrm{H}_{2} \mathrm{O}_{2} \quad$ Hydrogen peroxide

HbA1c Glycated hemoglobin

HCR High capacity runner

HDL High density lipoprotein

HNE 4-hydroxy-2-non-enal

HO-1 Heme oxygenase-1

IL-6 Interleukin 6

iNOS Inducible nitric oxide synthase

Keap1 Kelch-like ECH-associating protein 1

LDL Low density lipoprotein

LPS Lipopolysaccharides

Mn- Manganese superoxide dismutase

SOD

NADPH Reduced nicotinamide adenine dinucleotide phosphate

$\mathrm{NF}-\mathrm{k} \beta \quad$ Nuclear factor-k $\beta$

NO Nitric oxide

NQO-1 NAD(P)H dehydrogenase [quinone] 1

NRF-2 Nuclear factor (erythroid-derived 2)-like 2

PGC- Peroxisome-proliferator-activated receptor gamma

$1 \alpha$ coactivator $\alpha$

PGE2 Prostaglandin E2

PI3K Phosphatidylinositide 3-kinases

PKC Protein kinase $C$

PPAR Peroxisome proliferator-activated receptors

ROS Reactive oxygen species

SIRT-1 Sirtuin-1 NAD ${ }^{+}$-dependent class III histone deacetylases

SOD Superoxide dismutase

TAS Total antioxidant status

TLR4 Toll-like receptor 4

TNF- $\alpha$ Tumor necrosis factor alpha

\section{References}

Alcaín, F.J., Villalba, J.M., 2009. Sirtuin activators. Expert Opin. Ther. Pat. 19 (4), $403-$ 414.

Alissa, E.M., Ferns, G.A., 2012. Functional foods and nutraceuticals in the primary prevention of cardiovascular diseases. J. Nutr. Metab. 2012, 569486.

Almeida, L., Vaz-da-Silva, M., Falcao, A., Soares, E., Costa, R., Loureiro, A.I., Fernandes-Lopes, C., Rocha, J.F., Nunes, T., Wright, L., Soares-da-Silva, P., 2009. Pharmacokinetic and safety profile of transresveratrol in a rising multiple-dose study in healthy volunteers. Mol. Nutr. Food. 53 (1), S7-S15.

Andres-Lacueva, C., Urpı-Sarda, M., Zamora-Ros, R., Lamuela-Raventos, R.M., 2009. In: Fraga, C.G. (Ed.), Plant Phenolics and Human Health: Biochemistry, Nutrition and, Pharmacology. pp. 265-299.

Appeldoorn, M.M., Venema, D.P., Peters, T.H., Koenen, M.E., Arts, I.C.W., Vincken, J.P., Gruppen, H., Keijer, J., Hollman, P.C., 2009. Some phenolic compounds increase the nitric oxide level in endothelial cells in vitro. J. Agric. Food Chem. 57, 7693 7699.

Azorín-Ortuño, M., Yáñez-Gascón, M.J., Vallejo, F., Pallarés, F.J., Larrosa, M., Lucas, R., Morales, J.C., Tomás-Barberán, F.A., García-Conesa, M.T., Espín, J.C. 2011. Metabolites and tissue distribution of resveratrol in the pig. Mol. Nutr. Food Res. 55 (8), 1154-1168.

Baur, J.A., Sinclair, D.A., 2006. Therapeutic potential of resveratrol: the in vivo evidence. Nat. Rev. Drug Discov. 5, 493-506. 
Baur, J.A., Pearson, K.J., Price, N.L., Jamieson, H.A., Lerin, C., Kalra, A., Prabhu, V.V., Allard, J.S., Lopez-Lluch, G. Lewis, K. Pistell, P. J. Poosala, S., Becker, K.G., Boss, O., Gwinn, D., Wang, M., Ramaswamy, S., Fishbein, K.W., Spencer, R.G., Lakatta, E.G., Le Couteur, D., Shaw, R.J., Navas, P., Puigserver, P., Ingram, D.K., de Cabo, R., Sinclair, D.A., 2006. Resveratrol improves health and survival of mice on a highcalorie diet. Nature 444, 337-342.

Bhavnani, B.R., Cecutti, A., Gerulath, A., Woolever, A.C., Berco, M., 2001. Comparison of the antioxidant effects of equine estrogens, red wine components, vitamin $\mathrm{E}$, and probucol on low-density lipoprotein oxidation in postmenopausal women. Menopause 8, 408-419.

Bo, S., Ciccone, G., Castiglione, A., Gambino, R., De Michieli, F., Villois, P., Durazzo, M. Cavallo-Perin, P., Cassader, M., 2013. Anti-inflammatory and antioxidant effects of resveratrol in healthy smokers a randomized, double-blind, placebocontrolled, cross-over trial. Curr. Med. Chem. 20 (10), 1323-1331.

Boocock, D.J., Patel, K.R., Faust, G.E., Normolle, D.P., Marczylo, T.H., Crowell, J.A., Brenner, D.E., Booth, T.D., Gescher, A., Steward, W.P., 2007. Quantitation of trans-resveratrol and detection of its metabolites in human plasma and urine by high performance liquid chromatography. J. Chromatogr. B Analyt. Technol. Biomed. Life Sci. 848, 182-187.

Borriello, A., Cucciolla, V., Della Ragione, F., Galletti, P., 2010. Dietary polyphenols: focus on resveratrol, a promising agent in the prevention of cardiovascular diseases and control of glucose homeostasis. Nutr. Metab. Cardiovasc. Dis. 20 (8), 618-625.

Brasnyo, P., Molnar, G.A., Mohas, M., Marko, L., Laczy, B., Cseh, J., Mikolas, E., Szijarto, I.A., Merei, A., Halmai, R., Meszaros, L.G., Sumegi, B., Wittmann, I., 2011. Resveratrol improves insulin sensitivity, reduces oxidative stress and activates the Akt pathway in type 2 diabetic patients. Br. J. Nutr., 1-7.

Brown, V., Patel, K., Viskaduraki, M., Crowell, J.A., Perloff, M., Booth, T.D., Vasilinin, G., Sen, A., Schinas, A.M., Piccirilli, G., Brown, K., Steward, W.P., Gescher, A.J., Brenner, D.E., 2010. Repeat dose study of the cancer chemopreventive agent resveratrol in healthy volunteers: safety, pharmacokinetics and effect on the insulin-like growth factor axis. Cancer Res. 70 (22), 9003-9011.

Calamini, B., Ratia, K., Malkowski, M.G., Cuendet, M., Pezzuto, J.M., Santarsiero, B.D., Mesecar, A.D., 2010. Pleiotropic mechanisms facilitated by resveratrol and its metabolites. Biochem. J. 429, 273-282.

Candelario-Jalil, E., de Oliveira, A.C., Gräf, S., Bhatia, H.S., Hüll, M., Muñoz, E., Fiebich, B.L., 2007. Resveratrol potently reduces prostaglandin E2 production and free radical formation in lipopolysaccharide-activated primary rat microglia. J. Neuroinflammation 4,25.

Cao, Z., Li, Y., 2004. Potent induction of cellular antioxidants and phase 2 enzymes by resveratrol in cardiomyocytes: protection against oxidative and electrophilic injury. Eur. J. Pharmacol. 489, 39-48.

Carrizzo, A., Puca, A., Damato, A., Marino, M., Franco, E., Pompeo, F., Traficante, A., Civitillo, F., Santini, L., Trimarco, V., Vecchione, C., 2013. Resveratrol improves vascular function in patients with hypertension and dyslipidemia by modulating NO metabolism. Hypertension (Epub ahead of print).

Caruso, F., Tanski, J., Villegas-Estrada, A., Rossi, M., 2004. Structural basis for antioxidant activity of trans-resveratrol: ab initio calculations and crystal and molecular structure. J Agric Food Chem 52, 7279-7285.

Ceriello, A., Taboga, C., Tonutti, L., Quagliaro, L., Piconi, L., Bais, B., Da Ros, R., Motz, E., 2002. Evidence for an independent and cumulative effect of postprandial hypertriglyceridemia and hyperglycemia on endothelial dysfunction and oxidative stress generation: effects of short- and long-term simvastatin treatment. Circulation 106, 1211-1218.

Chen, C.K., Pace-Asciak, C.R., 1996. Vasorelaxing activity of resveratrol and quercetin in isolated rat aorta. Gen. Pharmacol. 27, 363-366

Chen, Z.H., Hurh, Y.J., Na, H.K., Kim, J.H., Chun, Y.J., Kim, D.H., et al., 2004. Resveratrol inhibits TCDD induced expression of CYP1A1 and CYP1B1 and catechol estrogen-mediated oxidative DNA damage in cultured human mammary epithelial cells. Carcinogenesis 25, 2005-2013.

Chen, C.Y., Jang, J.H., Li, M.H., Surh, Y.J., 2005. Resveratrol upregulates heme oxygenase-1 expression via activation of NF-E2-related factor 2 in PC12 cells. Biochem. Biophys. Res. Commun. 331 (4), 993-1000.

Chow, H.H., Garland, L.L., Hsu, C.H., Vining, D.R., Chew, W.M., Miller, J.A., Perloff, M., Crowell, J.A., Alberts, D.S., 2010. Resveratrol modulates drug- and carcinogenmetabolizing enzymes in a healthy volunteer study. Cancer Prev. Res. 3, 11681175.

Conti, V., Corbi, G., Russomanno, G., Simeon, V., Ferrara, N., Filippelli, W., Limongelli, F., Canonico, R., Grasso, C., Stiuso, P., Dicitore, A., Filippelli, A., 2012. Oxidative stress effects on endothelial cells treated with different athletes' sera. Med. Sci. Sports Exerc. 44 (1), 39-49.

Davinelli, S., Sapere, N., Zella, D., Bracale, R., Intrieri, M., Scapagnini, G., 2012. Effects of phytochemicals in Alzheimer's disease. Oxid. Med. Cell. Longev.. http:// dx.doi.org/10.1155/2012/386527.

de la Lastra, C.A., Villegas, I., 2007. Resveratrol as an antioxidant and pro-oxidant agent: mechanisms and clinical implications. Biochem. Soc. Trans. 35 (5), 11561160.

Dudka, J., Gieroba, R., Korga, A., Burdan, F., Matysiak, W., Jodlowska-Jedrych, B., Mandziuk, S., Korobowicz, E., Murias, M., 2012. Different effects of resveratrol on dose-related doxorubicin-induced heart and liver toxicity. Evid. Based Complement. Alternat. Med. 2012, 606183.

Dudzinski, D.M., Michel, T., 2007. Life history of eNOS: partners and pathways. Cardiovasc. Res. 75, 247-260.

Dudzinski, D.M., Igarashi, J., Greif, D., Michel, T., 2006. The regulation and pharmacology of endothelial nitric oxide synthase. Annu. Rev. Pharmacol. Toxicol. 46, 235-276.
Fang, J.G., Zhou, B., 2008. Structure-activity relationship and mechanism of the tocopherol-regenerating activity of resveratrol and its analogues. J. Agric. Food Chem. 56, 11458-11463.

Fang, J.G., Lu, M., Chen, Z.H., Zhu, H.H., Li, Y., Yang, L., Wu, L.M., Liu, Z.L., 2002. Antioxidant effects of resveratrol and its analogues against the free-radicalinduced peroxidation of linoleic acid in micelles. Chemistry 8, 4191-4198.

Fauconneau, B., Waffo-Teguo, P. Huguet, F., Barrier, L., Decendit, A., Merillon, J.M., 1997. Comparative study of radical scavenger and antioxidant properties of phenolic compounds from Vitis vinifera cell cultures using in vitro tests. Life Sci. $61,2103-2110$.

Feijóo, O., Moreno, A., Falqué, E., 2008. Content of trans- and cis-resveratrol in Galician white and red wines. J. Food Compost Anal. 21, 608-613.

Feng, Y., Wang, X.P., Yang, S.G., Wang, Y.J., Zhang, X., Du, X.T., Sun, X.X., Zhao, M., Huang, L., Liu, R.T., 2009. Resveratrol inhibits beta-amyloid oligomeric cytotoxicity but does not prevent oligomer formation. Neurotoxicology 30 (6), 986-995.

Franco, J.G., Lisboa, P.C., Lima, N.S., Amaral, T.A., Peixoto-Silva, N., Resende, A.C., Oliveira, E., Passos, M.C., Moura, E.G., 2013. Resveratrol attenuates oxidative stress and prevents steatosis and hypertension in obese rats programmed by early weaning. J. Nutr. Biochem. 24 (6), 960-966.

Frankel, E.N., Waterhouse, A.L., 1993. Inhibition of human LDL oxidation by resveratrol. Lancet 341, 1103-1104

Fremont, L., 2000. Biological effects of resveratrol. Life Sci. 66, 663-673.

Fremont, L., Belguendouz, L., Delpal, S., 1999. Antioxidant activity of resveratrol and alcohol-free wine polyphenols related to LDL oxidation and polyunsaturated fatty acids. Life Sci. 64, 2511-2521.

Frustaci, A., Kajstura, J., Chimenti, C., Jakoniuk, I., Leri, A., Maseri, A., Nadal-Ginard, B., Anversa, P., 2000. Myocardial cell death in human diabetes. Circ. Res. 87, $1123-1132$.

Fukui, M., Choi, H.J., Ting, Z.B., 2010. Mechanism for the protective effect of resveratrol against oxidative stress-induced neuronal death. Free Radic. Biol. Med. 49 (5), 800-813.

Gao, X., Belmadani, S., Picchi, A., Xu, X., Potter, B.J., Tewari-Singh, N., Capobianco, S., Chilian, W.M., Zhangn, C., 2007. Tumor necrosis factor-alpha induces endothelial dysfunction in Lepr(db) mice. Circulation 115, 245-254.

Gentile, M.T., Poulet, R., Di Pardo, A., Cifelli, G., Maffei, A., Vecchione, C., Passarelli, F., Landolfi, A., Carullo, P., Lembo, G., 2009. Beta-amyloid deposition in brain is enhanced in mouse models of arterial hypertension. Neurobiol. Aging 30 (2), 222-228.

Gescher, A.J., Steward, W.P., 2003. Relationship between mechanisms, bioavailibility, and preclinical chemopreventive efficacy of resveratrol: a conundrum. Cancer Epidemiol. Biomarkers Prev. 12, 953-957.

Ghanim, H., Sia, C.L., Abuaysheh, S., Korzeniewski, K., Patnaik, P., Marumganti, A., Chaudhuri, A., Dandona, P., 2010. An antiinflammatory and reactive oxygen species suppressive effects of an extract of Polygonum cuspidatum containing resveratrol. J. Clin. Endocrinol. Metab. 95, E1-E8.

Ghanim, H., Sia, C.L., Korzeniewski, K., Lohano, T., Abuaysheh, S., Marumganti, A., Chaudhuri, A., Dandona, P., 2011. A resveratrol and polyphenol preparation suppresses oxidative and inflammatory stress response to a high-fat, highcarbohydrate meal. J. Clin. Endocrinol. Metab. 96, 1409-1414.

Goldberg, D.M., Yan, J., Soleas, G.J., 2003. Absorption of three wine-related polyphenols in three different matrices by healthy subjects. Clin. Biochem. 36, 79-87.

Han, Y.S., Zheng, W.H., Bastianetto, S., Chabot, J.G., Quirion, R., 2004. Neuroprotective effects of resveratrol against $\beta$-amyloid induced neurotoxicity in rat hippocampal neurons: involvement of protein kinase C. Br. J. Pharmacol. 141 (6), 997-1005.

Hart, N., Sarga, L., Csende, Z., Koltai, E., Koch, L.G., Britton, S.L., Davies, K.J., Kouretas, D. Wessner, B. Radak, Z 2013. Resveratrol enhances exercise training responses in rats selectively bred for high running performance. Food Chem. Toxicol. (Epub ahead of print).

Hattori, R., Otani, H., Maulik, N., Das, D.K., 2002. Pharmacological preconditioning with resveratrol: role of nitric oxide. Am. J. Physiol. Heart Circ. Physiol. 282, H1988-H1995.

He, Y.G., Sun, Y.J., Xie, Y.X., Zheng, H., Zhang, Y.D., Guo, J., Xi, J.K., 2012. Resveratrol attenuates oxidant-induced mitochondrial damage in embryonic rat cardiomyocytes via inactivating GSK-3 $\beta$. Zhonghua. Xin. Xue. Guan. Bing. Za. Zhi. 40 (10), 858-863.

Hebbar, V., Shen, G., Hu, R., Kim, B.R., Chen, C., Korytko, P.J., Crowell, J.A., Levine, B.S., Kong, A.N., 2005. Toxicogenomics of resveratrol in rat liver. Life Sci. 76, 22992314.

Holvoet, P., 2004. Oxidized LDL and coronary heart disease. Acta Cardiol. 59, 479484

Howells, L.M., Berry, D.P., Elliott, P.J., Jacobson, E.W., Hoffmann, E., Hegarty, B., Brown, K., Steward, W.P., Gescher, A.J., 2011. Phase I randomized, double-blind pilot study of micronized resveratrol (SRT501) in patients with hepatic metastases - safety, pharmacokinetics, and pharmacodynamics. Cancer Prevention Res. 4, 1419-1425.

Howlett, J., Ashwell, M., 2008. Glycemic response and health: summary of a workshop. Am. J. Clin. Nutr. 87, 212S-216S

Inoue, H., Jiang, X.F., Katayama, T., Osada, S., Umesono, K., Namura, S., 2003. Brain protection by resveratrol and fenofibrate against stroke requires peroxisome proliferator-activated receptor $\alpha$ in mice. Neurosci. Lett. 352, 203-206.

Jang, J.H., Surh, Y.J., 2001. Protective effects of resveratrol on hydrogen peroxideinduced apoptosis in rat pheochromocytoma (PC12) cells. Mutat. Res. 496, 181190. 
Jang, M., Cai, L., Udeani, G.O., Slowing, K.V., Thomas, C.F., Beecher, C.W., Fong, H.H., Farnsworth, N.R. Kinghorn, A.D., Mehta, R.G., Moon, R.C., Pezzuto, J.M., 1997. Cancer chemopreventive activity of resveratrol, a natural product derived from grapes. Science 275, 218-220.

Jian, B., Yang, S., Chaudry, I.H., Raju, R., 2012. Resveratrol improves cardiac contractility following trauma-hemorrhage by modulating Sirt1. Mol. Med. $18,209-214$.

Johnson, J.J., Nihal, M., Siddiqui, I.A., Scarlett, C.O., Bailey, H.H., Mukhtar, H., Ahmad, N., 2011. Enhancing the bioavailability of resveratrol by combining it with piperine. Mol. Nutr. Food Res. 55, 1169-1176.

Juan, M.E., Vinardell, M.P., Planas, J.M., 2002. The daily oral administration of high doses of trans-resveratrol to rats for 28 days is not harmful. J. Nutr. 132, 257260.

Juan, S.H., Cheng, T.H., Lin, H.C., Chu, Y.L., Lee, W.S., 2005. Mechanism of concentration-dependent induction of heme oxygenase- 1 by resveratrol in human aortic smooth muscle cells. Biochem. Pharmacol. 69 (1), 41-48.

Juan, M.E., Maijo, M., Planas, J.M., 2010. Quantification of transresveratrol and its metabolites in rat plasma and tissues by HPLC. J. Pharm. Biomed. Anal. 51, 391398.

Karuppagounder, S.S., Pinto, J.T., Xu, H., Chen, H.L., Beal, M.F., Gibson, G.E., 2009 Dietary supplementation with resveratrol reduces plaque pathology in a transgenic model of Alzheimer's disease. Neurochem. Int. 54 (2), 111-118.

Kelsey, N.A., Wilkins, H.M., Linseman, D.A., 2010. Nutraceutical antioxidants as novel neuroprotective agents. Molecules 15 (11), 7792-7814.

Kern, T.S., 2007. Contributions of inflammatory processes to the development of the early stages of diabetic retinopathy. Exp. Diabetes Res. 2007, 95103.

Kim, Y.A., Lim, S.Y., Rhee, S.H., Park, K.Y., Kim, C.H., Choi, B.T., Lee, S.J., Park, Y.M., Choi, Y.H., 2006. Resveratrol inhibits inducible nitric oxide synthase and cyclooxygenase- 2 expression in $\beta$-amyloid-treated C6 glioma cells. Int. J. Mol. Med. 17 (6), 1069-1075.

Kimura, T., Takagi, H., Suzuma, K., Kita, M., Watanabe, D., Yoshimura, N., 2007. Comparisons between the beneficial effects of different sulphonylurea treatments on ischemia induced retinal neovascularization. Free Radic. Biol. Med. 43, 454-461.

Kitada, M., Kume, S., Imaizumi, N., Koya, D., 2011. Resveratrol improves oxidative stress and protects against diabetic nephropathy through normalization of $\mathrm{Mn}$ SOD dysfunction in AMPK/SIRT1-independent pathway. Diabetes 60 (2), 634 643.

Klinge, C.M., Blankenship, K.A., Risinger, K.E., Bhatnagar, S., Noisin, E.L. Sumanasekera, W.K., Zhao, L., Brey, D.M., Keynton, R.S., 2005. Resveratrol and estradiol rapidly activate MAPK signaling through estrogen receptors $\alpha$ and $\beta$ in endothelial cells. J. Biol. Chem. 280, 7460-7468.

Klinge, C.M., Wickramasinghe, N.S., Ivanova, M.M., Dougherty, S.M., 2008 Resveratrol stimulates nitric oxide production by increasing estrogen recepto $\alpha$-Src-caveolin-1 interaction and phosphorylation in human umbilical vein endothelial cells. Faseb J. 22 (7), 2185-2197.

Kohnen, S., Franck, T., Van Antwerpen, P., Boudjeltia, K.Z., Mouithys-Mickalad, A. Deby, C., Moguilevsky, N., Deby-Dupont, G., Lamy, M., Serteyn, D., 2007. Resveratrol inhibits the activity of equine neutrophil myeloperoxidase by a direct interaction with the enzyme. J. Agric. Food Chem. 55 (20), 8080-8087.

Kovanen, P.T., Pentikaïnen, M.O., 2003. Circulating lipoproteins as proinflammatory and anti-inflammatory particles in atherogenesis. Curr. Opin. Lipidol. 14, 411419.

Kowluru, R.A., Chan, P.S., 2007. Oxidative stress and diabetic retinopathy. Exp. Diabetes Res. 2007, 43603.

Kubota, S., Kurihara, T., Mochimaru, H., Satofuka, S., Noda, K., Ozawa, Y., Oike, Y. Ishida, S., Tsubota, K., 2009. Prevention of ocular inflammation in endotoxininduced uveitis with resveratrol by inhibiting oxidative damage and nuclear factor-kappaB activation. Invest. Ophthalmol. Vis. Sci. 50, 3512-3519.

Kumar, A., Naidu, P.S., Seghal, N., Padi, S.S.V., 2007. Neuroprotective effects of resveratrol against intracerebroventricular colchicine-induced cognitive impairment and oxidative stress in rats. Pharmacology 79 (1), 17-26.

la Porte, C., Voduc, N., Zhang, G., Seguin, I., Tardiff, D., Singhal, N., Cameron, D.W. 2010. Steady-State pharmacokinetics and tolerability of trans-resveratrol 2000 $\mathrm{mg}$ twice daily with food, quercetin and alcohol (ethanol) in healthy human subjects. Clin. Pharmacokinet. 49, 449-454.

Lagouge, M., Argmann, C., Gerhart-Hines, Z., Meziane, H., Lerin, C., Daussin, F., Messadeq, N., Milne, J., Lambert, P., Elliott, P., Geny, B., Laakso, M., Puigserver, P., Auwerx, J., 2006. Resveratrol improves mitochondrial function and protects against metabolic disease by activating SIRT1 and PGC- $1 \alpha$. Cell 127, 1109-1122.

Lasa, A., Churruca, I., Eseberri, I., Andrés-Lacueva, C., Portillo, M.P., 2012. Delipidating effect of resveratrol metabolites in 3T3-L1 adipocytes. Mol. Nutr. Food Res. 56 (10), 1559-1568.

Lee, J.H., Song, M.Y., Song, E.K., Kim, E.K., Moon, W.S., Han, M.K., Park, J.W., Kwon, K.B., Park, B.H., 2009. Overexpression of SIRT1 protects pancreatic beta-cells against cytokine toxicity by suppressing the nuclear factor-kappaB signaling pathway. Diabetes 58, 344-351.

Lee, S.M., Yang, H., Tartar, D.M., Gao, B., Luo, X., Ye, S.O., Zaghouani, H., Fang, D., 2011. Prevention and treatment of diabetes with resveratrol in a non-obese mouse model of type 1 diabetes. Diabetologia 54, 1136-1146.

Leighton, F., Cuevas, A., Guasch, V., Perez, D.D., Strobel, P., San Martin, A., Urzua, U. Díez, M.S., Foncea, R., Castillo, O., Mizón, C., Espinoza, M.A., Urquiaga, I., Rozowski, J., Maiz, A., Germain, A., 1999. Plasma polyphenols and antioxidants, oxidative DNA damage and endothelial function in a diet and wine intervention study in humans. Drug Exp. Clin. Res. 25, 133-141.
Li, Y., Cao, Z., Zhu, H., 2006. Upregulation of endogenous antioxidants and phase 2 enzymes by the red wine polyphenol, resveratrol in cultured aortic smooth muscle cells leads to cytoprotection against oxidative and electrophilic stress. Pharmacol. Res. 53 (1), 6-15.

Li, H., Xia, N., Förstermann, U., 2012. Cardiovascular effects and molecular targets of resveratrol. Nitric Oxide. 2012 Feb 15;26(2):102-10.

Li, H., Horke, S., Förstermann, U., 2013. Oxidative stress in vascular disease and its pharmacological prevention. Trends Pharmacol. Sci. (Epub ahead of print).

Liu, J.C., Chen, J.J., Chan, P., Cheng, C.F., Cheng, T.H., 2003. Inhibition of cyclic straininduced endothelin-1 gene expression by resveratrol. Hypertension 42, 1198 1205.

Liu, B.L., Zhang, X., Zhang, W., Zhen, H.N., 2007. New enlightenment of French Paradox: resveratrol's potential for cancer chemoprevention and anti-cancer therapy. Cancer Biol. Ther. 6, 1833-1836.

Losa, G.A., 2003. Resveratrol modulates apoptosis and oxidation in human blood mononuclear cells. Eur. J. Clin. Invest. 33, 818-823.

Lu, X.L., Ma, L., Ruan, L., Kong, Y., Mou, H., Zhang, Z., Wang, Z., Wang, J.M., Le, Y., 2010. Resveratrol differentially modulates inflammatory responses of microglia and astrocytes. J. Neuroinflammation 7, 46.

Maccarrone, M., Lorenzon, T., Guerrieri, P., Agro, A.F., 1999. Resveratrol prevent apoptosis in K562 cells by inhibiting lipoxygenase and cyclooxygenase activity. Eur. J. Biochem. 265, 27-34.

Manna, S.K., Mukhopadhyay, A., Aggarwal, B.B., 2000. Resveratrol suppresses TNFinduced activation of nuclear transcription factors NF-kB, activator protein-1, and apoptosis: potential role of reactive oxygen intermediates and lipid peroxidation. J. Immunol. 164, 6509-6519.

Marambaud, P., Zhao, H., Davies, P., 2005. Resveratrol promotes clearance of Alzheimer's disease amyloid- $\beta$ peptides. J. Biol. Chem. 280 (45), 37377-37382.

Marier, J.F., Vachon, P., Gritsas, A., Zhang, J., Moreau, J.P., Ducharme, M.P., 2002 Metabolism and disposition of resveratrol in rats: extent of absorption, glucuronidation, and enterohepatic recirculation evidenced by a linked-rat model. J. Pharmacol. Exp. Ther. 302, 369-373.

Maritim, A.C., Sanders, R.A., Watkins 3rd, J.B., 2003. Diabetes, oxidative stress, and antioxidants: a review. J. Biochem. Mol. Toxicol. 17, 24-38.

Meng, X., Maliakal, P., Lu, H., Lee, M.J., Yang, C.S., 2004. Urinary and plasma levels of resveratrol and quercetin in humans, mice, and rats after ingestion of pure compounds and grape juice. J Agric Food Chem. 52, 935-942.

Martinez, J., Moreno, J.J., 2000. Effect of resveratrol, a natural polyphenolic compound, on reactive oxygen species and prostaglandin production. Biochem. Pharmacol. 59, 865-870.

Mietus-Snyder, M., Gowri, M.S., Pitas, R.E., 2000. Class A scavenger receptor upregulation in smooth muscle cells by oxidized low density lipoprotein. Enhancement by calcium flux and concurrent cyclooxygenase-2 upregulation. J. Biol. Chem. 275, 17661-17670.

Miller, N.J., Rice-Evans, C.A., 1995. Antioxidant activity of resveratrol in red wine. Clin. Chem. 41, 1789.

Miura, T., Muraoka, S., Ikeda, N., Watanabe, M., Fujimoto, Y., 2000. Antioxidative and prooxidative action of stilbene derivatives. Pharmacol. Toxicol. 86, 203-208.

Mizutani, K., Ikeda, K., Kawai, Y., Yamori, Y., 2001. Protective effect of resveratrol on oxidative damage in male and female stroke-prone spontaneously hypertensive rats. Clin. Exp. Pharmacol. Physiol. 28, 55-59.

Mokni, M., Elkahoui, S., Limam, F., Amri, M., Aouani, E., 2007. Effect of resveratrol on antioxidant enzyme activities in the brain of healthy rat. Neurochem. Res. 32 (6), 981-987.

Morrow, J.D., Frei, B., Longmire, A.W., Gaziano, J.M., Lynch, S.M., Shyr, Y., Strauss W.E., Oates, J.A., Roberts 2nd, L.J., 1995. Increase in circulating products of lipid peroxidation (F2-isoprostane) in smokers. N. Engl. J. Med. 332, 1198-1203.

Movahed, A., Yu, L., Thandapilly, S.J., Louis, X.L., Netticadan, T., 2012. Resveratrol protects adult cardiomyocytes against oxidative stress mediated cell injury. Arch. Biochem. Biophys. 527, 74-80.

Nakata, R., Takahashi, S., Inoue, H., 2012. Recent advances in the study on resveratrol. Biol. Pharm. Bull. 35 (3), 273-279.

Narayanan, N.K., Nargi, D., Randolph, C., Narayanan, B.A., 2009. Liposome encapsulation of curcumin and resveratrol in combination reduces prostate cancer incidence in PTEN knockout mice. Int. J. Cancer 125, 1-8.

Ndisang, J.F., Lane, N., Syed, N., Jadhav, A., 2010. Up-regulating the heme oxygenase system with hemin improves insulin sensitivity and glucose metabolism in adult spontaneously hypertensive rats. Endocrinology 151, 549-560.

Nicholson, S.K., Tucker, G.A., Brameld, J.M., 2010. Physiological concentrations of dietary polyphenols regulate vascular endothelial cell expression of genes important in cardiovascular health. Br. J. Nutr. 103, 1398-1403.

Nisoli, E., Tonello, C., Cardile, A., Cozzi, V., Bracale, R., Tedesco, L., Falcone, S., Valerio, A., Cantoni, O., Clementi, E., Moncada, S., Carruba, M.O., 2005. Calorie restriction promotes mitochondrial biogenesis by inducing the expression of eNOS. Science 310 (5746), 314-317.

Nonomura, S., Kanagawa, H., Makimoto, A., 1963. Chemical constituents of polygonaceous plants. I. Studies on the components of Ko-jokon (Polygonum cuspidatum SIEB. et ZUCC.). Yakugaku Zasshi 83, 988-990.

Nunes, T., Almeida, L., Rocha, J.F., Falcão, A., Fernandes-Lopes, C., Loureiro, A.I., Wright, L., Vaz-da-Silva, M., Soares-da-Silva, P., 2009. Pharmacokinetics of trans-resveratrol following repeated administration in healthy elderly and young subjects. J. Clin. Pharmacol. 49, 1477-1482.

Olas, B., Wachowicz, B., 2002. Resveratrol and vitamin C as antioxidants in blood platelets. Thromb. Res. 106, 143-148. 
Olas, B., Wachowicz, B., Bald, E., Glowacki, R., 2004. The protective effects of resveratrol against changes in blood platelet thiols induced by platinum compounds. J. Physiol. Pharmacol. 55, 467-476.

Orallo, F., Alvarez, E., Camiña, M., Leiro, J.M., Gómez, E., Fernández, P., 2002. The possible implication of trans-Resveratrol in the cardioprotective effects of longterm moderate wine consumption. Mol. Pharmacol. 61, 294-302.

Otterbein, L.E., Choi, A.M., 2000. Heme oxygenase: colors of defense against cellular stress. Am. J. Physiol. Lung Cell. Mol. Physiol. 279, 1029-1037.

Pacher, P., Szabo, C., 2006. Role of peroxynitrite in the pathogenesis of cardiovascular complications of diabetes. Curr. Opin. Pharmacol. 6, 136-141.

Pacher, P., Beckman, J.S., Liaudet, L., 2007. Nitric oxide and peroxynitrite in health and disease. Physiol. Rev. 87, 315-424.

Palsamy, P., Subramanian, S., 2010. Ameliorative potential of resveratrol on proinflammatory cytokines, hyperglycemia mediated oxidative stress, and pancreatic $b$-cell dysfunction in streptozotocin-nicotinamide-induced diabetic rats. J. Cell. Physiol. 224, 423-432.

Papa, S., Skulachev, V.P., 1997. Reactive oxygen species, mitochondria, apoptosis and aging. Mol. Cell. Biochem. 174, 305-319.

Patel, N.V., Gordon, M.N., Connor, K.E., Good, R.A., Engelman, R.W., Mason, J., Morgan, D.G., Morgan, T.E., Finch, C.E., 2005. Caloric restriction attenuates A $\beta$ deposition in Alzheimer transgenic models. Neurobiol. Aging 26 (7), 995-1000.

Paul, B., Masih, I., Deopujari, J., Charpentier, C., 1999. Occurrence of resveratrol and pterostilbene in age-old darakchasava, an ayurvedic medicine from India. J. Ethnopharmacol. 68, 71-76.

Pearce, V.P., Sherrell, J., Lou, Z., Kopelovich, L., Wright, W.E., Shay, J.W., 2008. Immortalization of epithelial progenitor cells mediated by resveratrol. Oncogene 27, 2365-2374.

Polycarpou, E., Meira, L.B., Carrington, S., Tyrrell, E., Modjtahedi, H., Carew, M.A., 2013. Resveratrol 3-O-d-glucuronide and resveratrol 4'-O-d-glucuronide inhibit colon cancer cell growth: evidence for a role of A3 adenosine receptors, cyclin D1 depletion, and G1 cell cycle arrest. Mol. Nutr. Food Res.. http://dx.doi.org/ $10.1002 / \mathrm{mnfr} .201200742$

Prasad, K., 2012. Resveratrol, wine, and atherosclerosis. Int. J. Angiol. 21, 7-18.

Puca, A.A., Carrizzo, A., Ferrario, A., Villa, F., Vecchione, C., 2012. Endothelial nitric oxide synthase, vascular integrity and human exceptional longevity. Immun. Ageing 9, 26

Puca, A.A., Carrizzo, A., Villa, F., Ferrario, A., Casaburo, M., Maciąg, A., Vecchione, C., 2013. Vascular ageing: the role of oxidative stress. Int. J. Biochem. Cell Biol. 45 (3), 556-559.

Rains, J.L., Jain, S.K., 2011. Oxidative stress, insulin signaling, and diabetes. Free Radic. Biol. Med. 50, 567-575.

Rakici, O., Kiziltepe, U., Coskun, B., Aslamaci, S., Akar, F., 2005. Effects of resveratrol on vascular tone and endothelial function of human saphenous vein and internal mammary artery. Int. J. Cardiol. 105, 209-215.

Ramprasath, V.R., Jones, P.J.H., 2010. Anti-atherogenic effects of resveratrol. Eur. J. Clin. Nutr. 64 (7), 660-668.

Räthel, T.R., Samtleben, R., Vollmar, A.M., Dirsch, V.M., 2007. Activation of endothelial nitric oxide synthase by red wine polyphenols: impact of grape cultivars, growing area and the vinification process. J. Hypertens. 25, 541-549.

Ray, P.S., Maulik, G., Cordis, G.A., Bertelli, A.A., Bertelli, A., Das, D.K., 1999. The red wine antioxidant resveratrol protects isolated rat hearts from ischemia reperfusion injury. Free Rad. Biol. Med. 27, 160-169.

Rivière, C., Richard, T., Quentin, L., Krisa, S., Mérillon, J.M., Monti, J.P., 2007. Inhibitory activity of stilbenes on Alzheimer's $\beta$-amyloid fibrils in vitro. Bioorg. Med. Chem. 15 (2), 1160-1167.

Rocha, K.K.R., Souza, G.A., Ebaid, G.X., Seiva, F.R.F., Cataneo, A.C., Novelli, E.L.B., 2009. Resveratrol toxicity: effects on risk factors for atherosclerosis and hepatic oxidative stress in standard and high-fat diets. Food Chem. Toxicol. 47 (6) 1362-1367.

Romero-Pérez, A.I., Ibern-Gómez, M., Lamuela-Raventós, R.M., de La Torre-Boronat, M.C., 1999. Piceid, the major resveratrol derivative in grape juices. J. Agric. Food Chem. 47 (4), 1533-1536.

Ryan, M.J., Jackson, J.R., Hao, Y., Williamson, C.L., Dabkowski, E.R., Hollander, J.M. Alway, S.E., 2010. Suppression of oxidative stress by resveratrol after isometric contractions in gastrocnemius muscles of aged mice. J. Gerontol. A Biol. Sci. Med. Sci. 65 (8), 815-831.

Sabán, R.J., Alonso, A., Fabregate, M., de la Puerta, G.Q.C., 2013. Xanthine oxidase inhibitor febuxostat as a novel agent postulated to act against vascular inflammation. Antiinflamm. Antiallergy Agents Med. Chem. 12 (1), 94-99.

Saiko, P., Szakmary, A., Jaeger, W., Szekeres, T., 2008. Resveratrol and its analogs: defense against cancer, coronary disease and neurodegenerative maladies or just a fad? Mutat. Res. 658 (1-2), 68-94.

Salim, S., Asghar, M., Chugh, G., Taneja, M., Xia, Z., Saha, K., 2010. Oxidative stress: a potential recipe for anxiety, hypertension and insulin resistance. Brain Res. $1359,178-185$

Sato, M., Suzuki, Y., Okuda, T., Yokotsuka, K., 1997. Contents of resveratrol, piceid, and their isomers in commercially available wines made from grapes cultivated in Japan. Biosci. Biotechnol. Biochem. 61 (11), 1800-1805.

Scapagnini, G., Vasto, S., Abraham, N.G., Caruso, C., Zella, D., Galvano, F., 2011. Modulation of nrf2/are pathway by food polyphenols: a nutritional neuroprotective strategy for cognitive and neurodegenerative disorders. Mol. Neurobiol. 44 (2), 202.

Shah, A.M., Channon, K.M., 2004. Free radicals and redox signalling in cardiovascular disease. Heart 90, 486-487.

Sharma, S., Kumar, A., Arora, M., Kaundal, R.K., 2009. Neuroprotective potential of combination of resveratrol and 4 -amino 1,8 naphthalimide in experimental diabetic neuropathy: focus on functional, sensorimotor and biochemical changes. Free Radic. Res. 43, 400-408.

Sharma, S., Misra, C.S., Arumugam, S., Roy, S., Shah, V., Davis, J.A., Shirumalla, R.K., Ray, A., 2011. Antidiabetic activity of resveratrol, a known SIRT1 activator in a genetic model for type-2 diabetes. Phytother. Res. 25, 67-73.

Siemann, E.H., Creasy, L.L., 1992. Concentration of the phytoalexin resveratrol in wine. Am. J. Enol. Vitic, 43, 49-52.

Singh, C.K., Kumar, A., Hitchcock, D.B., Fan, D., Goodwin, R., LaVoie, H.A., Nagarkatti, P., DiPette, D.J., Singh, U.S., 2011. Resveratrol prevents embryonic oxidative stress and apoptosis associated with diabetic embryopathy and improves glucose and lipid profile of diabetic dam. Mol. Nutr. Food Res. 55, 1186-1196.

Singh, K.C., Kumar, A., LaVoie, A.L., Di Pipette, D.J., Singh, U.S., 2013. Diabetic complications in pregnancy: is resveratrol a solution? Exp. Biol. Med., 1-9.

Sinha, K., Chaudhary, G., Gupta, Y.K., 2002. Protective effect of resveratrol against oxidative stress in middle cerebral artery occlusion model of stroke in rats. Life Sci. 71, 655-665.

Smoliga, J.M., Vang, O., Baur, J.A., 2011. Challenges of translating basic research into therapeutics: resveratrol as an example. J. Gerontol. A Biol. Sci. Med. Sci. 67, 158-167.

Soleas, G.J., Diamandis, E.P., Goldberg, D.M., 1997. Resveratrol: a molecule whose time has come? And gone? Clin. Biochem. 30, 91-113.

Soufi, F.G., Mohammad-Nejad, D., Ahmadieh, H., 2012. Resveratrol improves diabetic retinopathy possibly through oxidative stress - nuclear factor $k \mathrm{~B}$ apoptosis pathway. Pharmacol. Rep. 64, 1505-1514.

Stocker, R., Yamamoto, Y., McDonagh, A.F., Glazer, A.N., Ames, B.N., 2000. Bilirubin is an antioxidant of possible physiological importance. Science 235 , 1043-1045.

Takahashi, S., Nakashima, Y., 2011. Repeated and long-term treatment with physiological concentrations of resveratrol promotes NO production in vascular endothelial cells. Br. J. Nutr. 104, 1-7.

Takahashi, S., Uchiyama, T., Toda, K., 2009. Differential effect of resveratrol on nitric oxide production in endothelial f-2 cells. Biol. Pharm. Bull. 32, 1840-1843.

Tang, B.L., Chua, C.E.L., 2008. SIRT1 and neuronal diseases. Mol. Asp. Med. 29 (3), $187-200$.

Tanno, M., Kuno, A., Yano, T., Miura, T., Hisahara, S., Ishikawa, S., Shimamoto, K., Horio, Y., 2010. Induction of manganese superoxide dismutase by nuclear translocation and activation of SIRT1 promotes cell survival in chronic heart failure. J. Biol. Chem. 285, 8375-8382.

Timmers, S., Konings, E., Bilet, L., Houtkooper, R.H., van de Weijer, T., Goossens, G.H., Hoeks, J., van der Krieken, S., Ryu, D., Kersten, S., Moonen-Kornips, E., Hesselink, M.K., Kunz, I., Schrauwen-Hinderling, V.B., Blaak, E.E., Auwerx, J., Schrauwen, P., 2011. Calorie restriction-like effects of 30 days of resveratrol supplementation on energy metabolism and metabolic profile in obese humans. Cell Metab. 14, 612-622.

Timmers, S., Auwerx, J., Schrauwen, P., 2012. The journey of resveratrol from yeast to human. Aging. 4,3

Turrens, J.F., Lariccia, J., Nair, M.G., 1997. Resveratrol has no effect on lipoprotein profile and does not prevent peroxidation of serum lipids in normal rats. Free Radic. Res. 27, 557-562.

Ungvari, Z., Labinskyy, N., Mukhopadhyay, P., Pinto, J.T., Bagi, Z., Ballabh, P., Zhang, C., Pacher, P., Csiszar, A., 2009. Resveratrol attenuates mitochondrial oxidative stress in coronary arterial endothelial cells. Am. J. Physiol. Heart. Circ. Physiol. 297, H1876-H1881.

Vang, O., Ahmad, N., Baile, C.A., Baur, J.A., Brown, K., Csiszar, A., Das, D.K., Delmas, D., Gottfried, C., Lin, H.Y., Ma, Q.Y., Mukhopadhyay, P., Nalini, N., Pezzuto, J.M., Richard, T., Shukla, Y., Surh, Y.J., Szekeres, T., Szkudelski, T., Walle, T., Wu, J.M., 2011. What is new for an old molecule? Systematic review and recommendations on the use of resveratrol. PLoS ONE 6, e19881.

Vecchione, C., Aretini, A., Marino, G., Bettarini, U., Poulet, R., Maffei, A., Sbroggiò, M., Pastore, L., Gentile, M.T., Notte, A., Iorio, L., Hirsch, E., Tarone, G., Lembo, G., 2006. Selective Rac-1 inhibition protects from diabetes-induced vascular injury. Circ. Res. 98 (2), 218-225.

Vecchione, C. Gentile, M.T. Aretini, A., Marino, G., Poulet, R., Maffei, A., Passarelli, F, Landolfi, A. Vasta, A., Lembo, G., 2007. A novel mechanism of action for statins against diabetes-induced oxidative stress. Diabetologia 50 (4), 874880.

Vecchione, C., Carnevale, D., Di Pardo, A., Gentile, M.T., Damato, A., Cocozza, G., Antenucci, G., Mascio, G., Bettarini, U., Landolfi, A., Iorio, L., Maffei, A., Lembo, G., 2009a. Pressure-induced vascular oxidative stress is mediated through activation of integrin-linked kinase 1 /betaPIX/Rac-1 pathway. Hypertension 54 (5), 1028-1034.

Vecchione, C., Frati, A., Di Pardo, A., Cifelli, G., Carnevale, D., Gentile, M.T., Carangi, R., Landolfi, A, Carullo, P. Bettarini, U., Antenucci, G. Mascio, G., Busceti, C.L. Notte, A., Maffei, A. Cantore, G.P., Lembo, G., 2009b. Tumor necrosis factoralpha mediates hemolysis-induced vasoconstriction and the cerebral vasospasm evoked by subarachnoid hemorrhage. Hypertension 54 (1), 150156.

Vincent, A.M., Russell, J.W., Sullivan, K.A., Backus, C., Hayes, J.M., McLean, L.L., Feldman, E.L., 2007. SOD2 protects neurons from injury in cell culture and animal models of diabetic neuropathy. Exp. Neurol. 208, 216-227.

Waite, K.A., Sinden, M.R., Eng, C., 2005. Phytoestrogen exposure elevates PTEN levels. Hum. Mol. Genet. 14, 1457-1463.

Walle, T. 2011. Bioavailability of resveratrol. Ann. NY Acad. Sci. 1215, 9-15.

Walle, T., Hsieh, F., DeLegge, M.H., Oatis Jr., J.E., Walle, U.K., 2004. High absorption but very low bioavailability of oral resveratrol in humans. Drug Metab. Dispos. $32,1377-1382$ 
Wallerath, T., Deckert, G., Ternes, T., Anderson, H., Li, H., Witte, K., Förstermann, U., 2002. Resveratrol, a polyphenolic phytoalexin present in red wine, enhances expression and activity of endothelial nitric oxide synthase. Circulation 106, $1652-1658$.

Wang, Y.I., He, F., Li, X.L., 2003. The neuroprotection of resveratrol in the experimental cerebral ischemia. Zhonghua Yi Xue Za Zhi. 83 (7), 534-536.

Wang, D., Hang, T., Wu, C., Liu, W., 2005. Identification of the major metabolites of resveratrol in rat urine by HPLC-MS/MS. J. Chromatogr. B Analyt. Technol. Biomed. Life Sci. 829, 97-106.

Wang, N., Ko, S.H., Chai, W., Li, G., Barrett, E.J., Tao, L., Cao, W., Liu, Z., 2011 Resveratrol recruits rat muscle microvasculature via a nitric oxidedependent mechanism that is blocked by TNF $\alpha$. Am. J. Physiol. Endocrinol. Metab. 300 E195-E201.

Wang, W., Yan, C., Zhang, J., Lin, R., Lin, Q., Yang, L., Ren, F., Zhang, J., Ji, M., Li, Y., 2013. SIRT1 inhibits TNF- $\alpha$-induced apoptosis of vascular adventitial fibroblasts partly through the deacetylation of FoxO1. Apoptosis 18 (6), 689-701.

Yang, F., Zhang, T., Ito, Y., 2001. Large-scale separation of resveratrol, anthraglycoside A and anthraglycoside B from Polygonum cuspidatum Sieb. et Zucc by high-speed counter-current chromatography. J. Chromatogr. A 919 , 443-448.

Yang, J., Dong, S., Jiang, Q., Kuang, T., Huang, W., Yang, J., 2013. Changes in expression of manganese superoxide dismutase, copper and zinc superoxide dismutase and catalase in Brachionus calyciflorus during the aging process PLoS One 8, 57186.

Zang, M., Xu, S., Maitland-Toolan, K.A., Zuccollo, A., Hou, X., Jiang, B., Wierzbicki, M. Verbeuren, T.J., Cohen, R.A., 2006. Polyphenols stimulate AMP-activated protein kinase, lower lipids, and inhibit accelerated atherosclerosis in diabetic LDL receptor-deficient mice. Diabetes 55, 2180-2191.

Zhang, H. Zhang J. Ungvari, Z, Zhang, C, 2009. Resveratrol improves endothelial function-role of TNF $\alpha$ and vascular oxidative stress. Arterioscler. Thromb. Vasc. Biol. 29, 1164-1171.

Zhang, H., Morgan, B., Potter, B.J., Ma, L., Dellsperger, K.C., Ungvari, Z., Zhang, C. 2010. Resveratrol improves left ventricular diastolic relaxation in type diabetes by inhibiting oxidative/nitrative stress: in vivo demonstration with magnetic resonance imaging. Am. J. Physiol. Heart. Circ. Physiol. 299, H985H994.

Zhang, J., Chen, J., Yang, J., Xu, C.W., Pu, P., Ding, J.W., Jiang, H., 2013. Resveratrol attenuates oxidative stress induced by balloon injury in the rat carotid artery through actions on the ERK1/2 and NF-kappa B pathway. Cell. Physiol. Biochem. 31 (2-3), 230-241.

Zhuang, H., Kim, Y.S., Koehler, R.C., Doré, S., 2003. Potential mechanism by which resveratrol, a red wine constituent, protects neurons Ann. N. Y. Acad. Sci. 993 276-288. 